\title{
The Swiss Corona Stress Study
}

Corresponding author: Dominique de Quervain (dominique.dequervain@unibas.ch)

Co-authors in alphabetical order:

Amanda Aerni

Ehssan Amini

Dorothée Bentz

David Coynel

Christiane Gerhards

Bernhard Fehlmann

Virginie Freytag

Andreas Papassotiropoulos

Nathalie Schicktanz

Thomas Schlitt

Anja Zimmer

Priska Zuber

Affiliation: University of Basel, Transfaculty Research Platform Molecular and Cognitive Neurosciences, Faculty of Psychology and Medical Faculty, Birmannsgasse 8, CH-4055 Basel, Switzerland 


\section{Abstract}

The mental consequences of the COVID-19 pandemic and the strict lockdown measures implemented by governments world-wide to fight it are currently unknown. We performed an online survey study in Switzerland and analyzed data acquired during confinement (wave 1) and during partial lifting of measures (partial deconfinement) (wave 2). Wave 1: Data from over 10'000 individuals living in Switzerland were collected between April 6 and 8, 2020, starting 3 weeks after the beginning of confinement. While $24.4 \%$ of the participants reported no change in stress levels, $49.6 \%$ of the participants reported an increase in stress levels during confinement as compared to the time before the COVID-19 pandemic. We identified several potential sources for people feeling more stressed during confinement, such as the burden related to changes at work or school, problems with childcare or not being able to spend more time with others. The changes in stress levels were highly correlated with changes in depressive symptoms. $57 \%$ of the participants reported an increase in depressive symptoms. Further, the prevalence of moderately severe or severe depressive symptoms (PHQ-9 score $\geq 15$ ) increased from $3.4 \%$ before the COVID-19 pandemic to $9.1 \%$ during confinement. Interestingly, $26 \%$ of participants showed a decrease in stress level during confinement, suggesting that for those individuals the confinement involved a reduction of stressors and/or resulted in more time for recovery. Finally, we identified several behaviors amenable to change that were related to a reduced increase in stress level and depressive symptoms during confinement. 
Wave 2: Data from over 10'000 individuals living in Switzerland were collected between May 11 and June 1, 2020 during partial deconfinement. As for wave 1, we observed diverse reactions with regard to stress levels: While $28 \%$ of the participants reported no change in stress levels, $40 \%$ of the participants reported an increase in stress levels during partial deconfinement as compared to the time before the COVID-19 pandemic. We identified similar sources for people feeling more stressed as during confinement and the changes in stress levels were highly correlated with changes in depressive symptoms. $49.5 \%$ of the participants reported an increase in depressive symptoms. Further, the prevalence of moderately severe or severe depressive symptoms (PHQ-9 score $\geq 15)$ remained elevated with a prevalence rate of $11.7 \%$. With regard to changeable behaviors during the pandemic, we found (as in wave 1) that spending more time pursuing new projects, spending more time pursuing hobbies at home, and light physical exercise were related to less stress increase.

A comparison between the two waves indicated that while the waves did not substantially differ in the distributions of changes in stress levels or depressive symptoms, they did differ with regard to the distribution of anxiety ratings. Specifically, anxiety levels decreased from wave 1 to wave 2 .

Finally, we identified risk and resilience factors with regard to the development of depressive symptoms (present in both waves): A history of a prior psychiatric disorder was a risk factor for developing moderately severe or severe depressive symptoms during the pandemic. In a resilient group of people who had none or only minimal depressive symptoms before and during the pandemic, older people ( $\geq 55$ years), men 
and individuals with no history of prior psychiatric disorder were overrepresented. Thus, advanced age, male gender and the absence of prior psychiatric disorder were identified as resilience factors.

\section{Introduction}

To contain the COVID-19 pandemic, governments all over the globe have set into place unprecedented restrictions to people's daily lives, such as orders for self-isolation and quarantines as well as shutdowns of educational institutions, recreational facilities and businesses. Besides the dramatic consequences for economies, these restrictions most likely have both immediate and long-term impact on mental health.

An approximation of the consequences of COVID-19 and its subsequent ramifications on our daily lives can be drawn from stress research. Stress can be conceptualized as being confronted with a challenging situation that requires some kind of adaptation [1]. With the imminent threat of getting infected, the problems arising from the governmental restrictions and the uncertainty about how and when people will be able to return to their normal routine, this situation is challenging for many. Humans are generally well-equipped to deal with challenges as our stress system is highly adaptive, and during phases of stress, anxiety and worries are normal reactions. However, since stress is a well-known risk factor for mental disorders, vulnerable individuals may be at increased risk to develop stress-related mental health problems in the current situation [2]. 
A recent position paper published in Lancet Psychiatry on April 15, 2020 explored psychological, social and neuroscientific consequences of the COVID-19 to inform immediate priorities and long-term strategies for public health and research. The position paper was based on surveys of the United Kingdom population. It emphasizes the immediate priority to collect data on the mental health effects of the COVID-19 pandemic across the whole population and vulnerable groups [3].

Until solid data are available, we can only speculate about the impact of COVID-19 on mental health. It is also possible that the occurrence of a common health crisis might trigger protective factors with regard to mental well-being. For example, in the wake of past national disasters that posed a possible threat to physical integrity (such as September 11, 2001) suicide rates have declined [4]. It was hypothesized that this effect might have been driven by increased social cohesion and stronger support from friends and families [4], [5]. It is also possible that the governmental restrictions during this crisis may entail relieving aspects, at least for some individuals. The generation of knowledge about the mental health consequences and the identification of risk and resilience factors is of utmost importance to inform about needs during the current and subsequent outbreaks of COVID-19 or any future outbreak of this sort.

The current study, the "Swiss Corona Stress Study", investigates how the Swiss population adapts to the COVID-19 outbreak and the confinement measures in Switzerland. It sets out to identify risk- and resilience factors, in particular behaviors amenable to change. Stress research has a long history and various evidence-based 
interventions to counter stress have been proposed [5]-[7]. However, since the COVID-19 pandemic is unprecedented, we lack evidence about whether the existing interventions are effective in the context of a pandemic lockdown.

In a first stage of data analysis we focused on investigating how subjective stress levels are affected during the time of confinement (wave 1), identifying important factors related to changes in stress levels, including potential resilience factors, and investigating the prevalence of moderately severe to severe depressive symptoms before the COVID-19 pandemic and during confinement. In a second stage of data analysis we focused on the same analysis as in stage 1 , but now for the time of partial deconfinement (wave 2), and additionally compared the two waves and investigated potential risk and resilience factors with regard to the development of depressive symptoms. 


\section{Methods}

\section{Study design and participants}

Wave 1: We conducted an anonymized survey investigating the impact of the pandemic and the confinement (restrictions put into force on March 16, 2020 by the Swiss government) on mental well-being in Switzerland. The survey went online on April 6, 2020, i.e. three weeks after lockdown onset. Participants from all regions of Switzerland were recruited through referrals to the study by a media release of the University of Basel, local newspapers, radio interviews and social media. For data analysis, all participants living in Switzerland of at least 14 years of age who completed the survey by April 8, 2020 were included. 10'472 participants fulfilled the inclusion criteria. No study protocol approval by the local Ethic committee was necessary, as the survey was anonymized. All participants gave written informed consent for participation. Participants did not receive any monetary compensation. However, they received recommendations for stress reduction on the basis of the information given in the survey.

Wave 2: A second wave of participants was acquired in the phase of the partial deconfinement between May 11 and June 1, 2020. On April 27, hairdressers and gardening centers reopened, on May 11, mandatory schools and all stores reopened. Participants from all regions of Switzerland were recruited through referrals to the study by a media release of the University of Basel, local newspapers, radio interviews and social media. For data analysis, all participants living in Switzerland of at least 14 years 
of age, who completed the survey within the second acquisition phase, were included. Participants who indicated having participated in the first acquisition wave were excluded. 10'303 participants fulfilled the inclusion criteria. For wave 2, we have substituted the question regarding the effects of the changes related to the pandemic "I feel relieved in the current situation" by the following three questions: 1) "I feel relieved by the reduction of private obligations", 2) "I feel relieved by the reduction of professional/school obligations", 3) "I have more time for relaxation". Further questions that were added in the second wave are: "having participated in this survey before", "change in TV consumption", "I feel I have less/more control of my own situation", and "working in an area that currently involves direct customer contact (in compliance with the safety precautions)". The questions regarding "having animals", "being helped with the shoppings", and "helping others with their shopping" were deleted in wave 2 because of the absence of relations to variables of interest.

\section{Procedure and outcomes}

Potential participants visited a webpage, www.coronastress.ch, where they could choose one of three possible national languages. If participants were interested to take part in the survey, they were directed to the questionnaire. The first page of the survey contained study information and informed consent. Only after agreement to the informed consent, the survey started and normally could be completed within 15 minutes. The software SoSci Survey was used for online assessment [8]. Only the day 
of participation was recorded in SoSci Survey, while IP-addresses and timestamps were not recorded.

In the first part of the survey we collected sociodemographic and further relevant data including gender, age, nationality, country of residence, living situation, family status, religiousness, burden of childcare, highest educational level, profession, relevant pre-existing physical or psychiatric conditions, coronavirus diagnostic status, acceptance of taken federal measures, fears related to the coronavirus, burdens arising from the federal measures, changes in consumption of food / gaming / drugs / sleeping pills and tranquilizers, changed habits, frequency of information seeking about news on the corona crisis, changes in circadian rhythm and eating routines, level of physical activity and meditation before the COVID-19 pandemic and during the lockdown. Afterwards, the following outcomes of interest were assessed: stress level, anxiety level and depressive symptoms before the COVID-19 pandemic (i.e. during the two first weeks of February 2020, rated retrospectively) and during the past two weeks of the lockdown (counted from the date the survey was filled in). Stress and anxiety levels were assessed using 6-point likert scales ranging from 0 (not at all) to 5 (extremely strong). Depressive scores were assessed by the "Patient Health Questionnaire 9" PHQ-9, a 9-question self-rating questionnaire to screen for the presence and severity of depression. We used German, French and Italian translations of the PHQ-9 (see [9] for English version). At the end of the survey, participants received automated recommendations for stress reduction on the basis of the information given in the 
survey, such as performing physical activities or mindfulness exercises. All questions needed to be answered in order to complete the survey.

\section{Statistical analyses}

Data was analysed with $R$ version 3.6.2. We applied linear models in combination with ANOVAs for nominal variables, Pearson correlations for interval variables and Spearman's rank correlations for ordinal variables. For stress, anxiety and depression, we calculated for each of the three variables a difference score by subtracting the rating before the pandemic from the rating during the confinement phases (we refer to the difference score as "change in stress, anxiety, or depression", respectively). Therefore, positive values indicate increased stress / anxiety / depression scores during the confinement phases as compared to before. For a first overview, the statistical models consisted of one dependent variable (one of the main outcome variables) and one independent variable. In the case of linear models, the strength of the relationships was obtained by extracting the correlation value $r$ from each corresponding linear model (i.e. normalized regression coefficient). We only report relationships with at least a small effect size $(|r| \geq 0.1)$.

The change in the number of participants reporting moderately severe to severe depression symptoms (PHQ-9 score $\geq 15$ ) before and during the confinement phases was further compared by means of a McNemar's chi-squared test. 


\section{Matching of recruitment waves}

We observed noticeable differences in socio-demographics characteristics between participants in the two recruitment waves (see supplementary Table 1). In order to ensure robustness of outcomes comparisons (stress, anxiety, depressive symptoms) between the two waves relative to these differences, a sample matching procedure was applied. We used the nearest-neighbor method implemented in the R package Matchlt, considering 'Wave1' participants as treatment units and 'Wave2' as controls, with possible replacement. Samples were thus matched for gender (excluding participants not included in "male" or "female" categories to avoid classes with extremely low frequencies), age, living status, religious status, living area, current professional activity, education, canton group (German, French or Italian speaking), and age of children category (see above).

This yielded a total of $N=10^{\prime} 438$ participants selected from Wave 1 and $N=5^{\prime} 120$ participants from Wave 2 matching for the aforementioned socio-demographic variables. Weights derived from the matching procedure were included in all subsequent analyses involving matched populations (e.g. chi-square tests).

\section{Comparison of study outcomes between waves}

Levels of stress, anxiety and PHQ scores during the pandemic were compared between the two waves. Chi-squares tests of homogeneity were applied to assess differences 
between the two recruitment in terms of categorical distribution of the outcomes. Population comparisons were systematically performed considering both overall samples and matched samples. Differences between waves were interpreted only for observed Cramer's $\vee$ effect sizes $\geq 0.1$ (corresponding to at least a small effect) in both unmatched and matched populations. The same analyses were performed for other collected variables related to the pandemic. For quantitative variables, distributions between Wave 1 and Wave 2 populations were compared using a Kruskall-Wallis test, while the magnitude of the effect was assessed by means of Epsilon-squared.

Risk and resilience factors analysis

We defined 'vulnerable' individuals as those reporting PHQ scores $\geq 15$ during the pandemic (corresponding to 'Moderately Severe' and 'Severe' categories), while having a PHQ score $<15$ before the pandemic. 'Resilient' subjects were defined as participants reporting PHQ scores $\leq 4$ ('None-Minimal') both before and during the pandemic. In order to identify risk and resilience factors, we first applied Chi-square tests comparing the distribution of demographic factors between each defined subset (resilient or vulnerable) and all remaining individuals. Variables showing at least small effect sizes (Cramer's $V \geq 0.1$ ) across the two waves were further investigated under a logistic regression model. Only associations with an odds ratio (OR) corresponding to at least small effect cohen's $\mathrm{d}\left(\log (O R) * \frac{\sqrt{3}}{\pi}>0.2\right)$ across the two waves were interpreted. Marginal effects from logistic regression were obtained using the ggeffect command 
from the R package ggeffects.

For these analyses, in order to avoid individual variable categories with low frequencies, the following demographic variables were grouped: profession (working in a sector affected by pandemic restrictions, working in a sector not affected by pandemic restrictions, retired or disability, house-wife/husband, job seeking, school-study-apprenticeship); age group (14-24, 25-34, 35-44, 45-54, 55-64, >=65), age of older children (No children, [0-1], ]1-5], ]5-10], ]10-18], > 18); education (university level, no university level); household (living alone, not alone). In addition, participants with reported gender different from 'male' or 'female' were discarded from these analyses. For comparing the effect of age, sex and prior psychiatric disorder on the probability to belong to the lowest $\mathrm{PHQ}$ category ( $\mathrm{PHQ} \leq 4$, None-minimal) before and during the crisis, we applied a mixed logistic regression model: interaction term between time (before/during pandemic) and each factor was evaluated by means of Nagelkerke pseudo-R2 obtained from the comparison between the additive model and the model with interaction.

\section{Role of funding source}

The study was funded by the University of Basel. All authors had full access to all the data in the study and had final responsibility for the decision to submit for publication. None of the authors had any conflict of interest. 


\section{Results}

\section{Wave 1}

\section{Population descriptive statistics}

Between April 6 and April 8, 2020 we received 10'472 complete responses from participants living in Switzerland (see Supplementary Data). The majority of participants were Swiss citizens (88.2\%). 62.1\% of the participants were from the German speaking cantons, $30.9 \%$ from the French speaking cantons and $7 \%$ from the Italian speaking canton of Ticino. $71 \%$ of the participants were female; the participants were between 14 and 92 years old (mean/M $=40.3 \mathrm{y}$, median/Mdn $=39 \mathrm{y}, \mathrm{SD}=13.6 \mathrm{y})$. Most participants $(93.6 \%)$ stated to be devoid of any flu-like symptoms and had not been tested for COVID-19 infection, 3.2\% were not tested but had flu-like symptoms, $2.6 \%$ were tested negative for COVID-19 and $0.5 \%$ were tested positive. $19.8 \%$ of the participants were living alone, $45.7 \%$ indicated to have children, $39.4 \%$ to have animals. $51.9 \%$ of the participants had a degree in higher education. $70.4 \%$ of the participants were working, $8.5 \%$ self-employed. $16.6 \%$ of the participants were impacted by short-time work or closure; $8.5 \%$ of the participants were employed by supermarkets, in the food sector or in the delivery of goods; $7.6 \%$ were working with patients or in the care sector; $6.9 \%$ were teachers. $19.8 \%$ of the participants recorded pre-existing health conditions among which respiratory, cardio-vascular or other diseases and $23.6 \%$ reported previous 
psychiatric disorders, including depression (14.6\%) and anxiety disorders (13.3\%). For further details see Supplementary Data.

\section{Change in stress levels}

During confinement, stress levels were increased on average (difference score: mean $=$ 0.48, median $=0, s d=1.89 ;$ before the pandemic: mean $=1.97$, median $=2, s d=1.36$; during confinement: mean $=2.45$, median $=3, s d=1.59$, see Figure 1 ). While $49.6 \%$ of participants perceived an increase in stress, $26 \%$ of the participants perceived less stress and $24.4 \%$ perceived an equal amount of stress during confinement as compared to the time before the pandemic (see Figure 2a).

\section{Relation to socio-demographic variables}

None of the variables reflecting sociodemographic characteristics were associated with a change in stress levels (all $|r|<0.1)$.

\section{Relation to burdens during confinement}

The burdens due to the pandemic-related changes (see table 1 for detailed overview) that were most strongly associated with an increase in stress levels were: the burden due to changes at school $(r=0.39)$ and at work $(r=0.37)$, the burden of childcare $(r=$ $0.30)$, the burden of living alone $(r=0.30)$, the burden due to thoughts about the future $(r=0.27)$, the burden of not being able to spend more time privately with others $(r=$ $0.25)$, the burden of reduced personal freedom $(r=0.23)$, and being overwhelmed by the switch to digital media / classes / teaching $(r=0.20)$. 


\section{Relation to reliefs during confinement}

The reliefs due to the pandemic-related changes that were most strongly associated with a decrease in stress levels were: feeling relieved in the current situation $(r=-0.50)$, and feeling good to spend more time with family / partner / child(ren) $(r=-0.15)$.

\section{Relation to depressive symptoms (total score PHQ-9)}

The change in stress levels was highly positively correlated with increased depressive symptoms $(r=0.57)$. Stress levels were also positively correlated with cross-sectional depressive scores, both before the pandemic $(r=0.48)$ and during confinement $(r=$ $0.60)$.

\section{Relation to anxiety levels}

The change in stress levels was highly correlated with change in anxiety levels $(r=$ 0.53). Stress levels were also positively correlated with cross-sectional anxiety levels, both before the pandemic $(r=0.46)$ and during confinement $(r=0.63)$.

\section{Relation to changeable behaviors during confinement}

The increase in stress levels was lower in participants who were able to spend more time pursuing other / new projects $(r=-0.19)$ or hobbies at home $(r=-0.18)$, performing intense $(r=-0.15)$ or light $(r=-0.11)$ physical exercise during confinement. In contrast, stress increase was higher in participants who informed themselves more frequently about coronavirus news $(r=0.11)$. 


\section{Change in depressive symptoms}

During confinement, depression scores were increased on average (difference score: mean $=1.88$, median $=1, \mathrm{sd}=4.50 ;$ before pandemic: mean $=4.63$, median $=4, \mathrm{sd}=$ 4.21; during confinement: mean $=6.51$, median $=5, s d=5.37$, see Figure 3 ). $23.5 \%$ of the participants had a lower depression score, $19.5 \%$ had the same score, and $57 \%$ of the participants had a higher score for the time during confinement as compared to the time before the pandemic (see Figure 4). The proportion of participants who indicated to suffer from at least moderate depressive symptoms $(P H Q-9 \geq 10)$ before the pandemic was $11.8 \%$. This proportion is slightly higher than the proportion reported for the general $\begin{array}{llllll}\text { population } & \text { of } & 8.6 \% & \text { for } & \text { the } & \text { year }\end{array}$ (https://www.obsan.admin.ch/de/indikatoren/depressionssymptome). In our study, this proportion raised to $24.7 \%$ for the time of confinement. The proportion of all participants suffering from at least moderately severe depression (PHQ-9 score $\geq 15)$ increased from $3.4 \%$ before the pandemic to $9.1 \%$ during confinement (Mc Nemar test $p$-value $<$ 2.2e-16; Cohen's g = 0.33).

\section{Relation to burdens during confinement}

The burdens due to the pandemic-related changes (see table 1 for detailed overview) that were most strongly associated with an increase in depression score were: the burden of living alone $(r=0.42)$, the burden due to changes at work $(r=0.37)$ or at school $(r=0.37)$, the burden due to thoughts about the future $(r=0.33)$, the burden of not being able to spend more time privately with others $(r=0.31)$, the burden of reduced personal freedom $(r=0.29)$, the burden of childcare for people with children $(r=0.28)$, 
and the burden of not being able to spend more time with others in the working life $(r=$ $0.28)$.

\section{Relation to reliefs during confinement}

The reliefs due to the pandemic-related changes that were most strongly associated with a decrease in depression score were: feeling relieved in the current situation $(r=$ -0.42 ) and feeling good to spend more time with family / partner /child(ren) $(r=-0.17)$.

\section{Relation to anxiety levels}

The change in anxiety was highly correlated with change in depression $(r=0.49)$. Anxiety levels were positively correlated with cross-sectional depression scores before the pandemic $(r=0.46)$ and during confinement $(r=0.56)$.

\section{Relation to changeable behaviors during confinement}

The increase in depression score was higher in participants who changed their sleep schedule $(r=0.22)$ or eating schedule $(r=0.21)$, did inform themselves more frequently about the coronavirus $(r=0.11)$, and maintained social contacts by increasingly using smartphones / computers / telephones $(r=0.10)$. In contrast, the increase in depression score was lower in participants who were able to increasingly pursue other/new projects $(r=-0.17)$ or pursue hobbies at home $(r=-0.17)$, to perform more light $(r=-0.13)$ or intense $(r=-0.12)$ physical activity. 


\section{Changes in anxiety levels}

During confinement, anxiety levels were increased on average (difference score: mean $=1.01$, median $=1, \mathrm{sd}=1.55 ;$ before pandemic: mean $=1.01$, median $=1, \mathrm{sd}=1.24$; during the confinement: mean $=2.02$, median $=2, s d=1.59) .10 .6 \%$ of participants felt less anxiety, $32.1 \%$ felt the same amount of anxiety, and $57 \%$ of participants were more anxious during confinement as before the pandemic.

\section{Relation to burdens during confinement}

The burdens due to the pandemic-related changes that were associated with increased anxiety levels were: the burden of thoughts about the future $(r=0.35)$, fear to get infected with the virus $(r=0.32)$, burden of living alone $(r=0.31)$, burden of change at work $(r=0.31)$ and at school $(r=0.26)$, fear of dying because of the virus $(r=0.29)$, the burden of change at school / high school /college / university / in training $(r=0.26)$, fear that a close person could die because of the virus $(r=0.26)$ or get infected $(r=0.25)$.

\section{Relation to reliefs during confinement}

The relief due to the pandemic-related changes that was associated with a decrease in anxiety levels was: feeling relieved in the current situation $(r=-0.27)$.

\section{Relation to changeable behaviors during confinement}

An increase in anxiety level was higher in participants who maintained social contacts by increasingly using smartphones / computers / telephones $(r=0.13)$, did inform themselves more frequently about coronavirus news $(r=0.15)$, changed their sleep $(r=$ 
0.13 ) or eating schedule $(r=0.10)$. In contrast, the increase in anxiety level was lower in participants who were able to engage more in intense physical activity $(r=-0.11)$.

\section{Wave 2}

\section{Population descriptive statistics}

Between May 11 and June 1, 2020 we received 10'303 complete responses from participants living in Switzerland (see Supplementary Data). The majority of participants were Swiss citizens (86\%). $82.2 \%$ of the participants were from the German speaking cantons, $13.9 \%$ from the French speaking cantons and 3.9\% from the Italian speaking canton of Ticino. $74.2 \%$ of the participants were female; the participants were between 14 and 90 years old $($ mean $=43.31 \mathrm{y}$, median $=44 \mathrm{y}, \mathrm{SD}=15.93 \mathrm{y})$. Most participants $(92.2 \%)$ stated to be devoid of any flu-like symptoms and had not been tested for

COVID-19 infection, $1 \%$ were not tested but had flu-like symptoms; $6.2 \%$ of the participants were tested negative for COVID-19 and 0.6\% participants were tested positive. $21.1 \%$ of the participants were living alone, $46.3 \%$ indicated to have children. $41.2 \%$ of the participants had a degree in higher education. $62.7 \%$ of the participants were working, $9.5 \%$ self-employed. $10.8 \%$ of the participants were impacted by short-time work or closure; $14.3 \%$ of the participants were employed in the food sector, in the delivery of goods or had direct customer contact; $10.1 \%$ were working with patients or in the care sector; $5.6 \%$ were teachers. $24.4 \%$ of the participants recorded pre-existing health conditions among which respiratory, cardio-vascular or other 
diseases and $24.8 \%$ reported previous psychiatric disorders, including depression $(17.5 \%)$ and anxiety disorders (11.4\%). For further details see Supplementary Data.

\section{Change in stress levels}

During partial deconfinement, stress levels were increased on average (difference score: mean $=0.19$, median $=0, s d=1.96$; before the pandemic: mean $=2.06$, median $=2, \mathrm{sd}=1.47$; during partial deconfinement: mean $=2.25$, median $=2, \mathrm{sd}=1.7$, see Figure $5 a$ ). While $40 \%$ of participants perceived an increase in stress, $32 \%$ of the participants perceived less stress and $28 \%$ perceived an equal amount of stress during partial deconfinement as compared to the time before the pandemic (see Figure 5a).

\section{Relation to socio-demographic variables}

None of the variables reflecting sociodemographic characteristics were associated with a change in stress levels (all $|r|<0.1)$.

\section{Relation to burdens during partial deconfinement}

The burdens due to the pandemic-related changes (see table 2 for detailed overview) that were most strongly associated with an increase in stress levels were: the burden due to changes at school $(r=0.35)$ and at work $(r=0.34)$, the burden of living alone $(r=$ $0.28)$, the burden of not being able to spend more time privately with others $(r=0.26)$, the burden of childcare $(r=0.26)$, the burden due to thoughts about the future $(r=0.25)$, the burden of reduced personal freedom $(r=0.24)$, the burden to keep the two meter 
security distance $(r=0.20)$, the burden of not being able to spend more time at work with others $(r=0.19)$, and the burden of increased conflicts at home $(r=0.18)$.

\section{Relation to reliefs during partial deconfinement}

The reliefs due to the pandemic-related changes that were most strongly associated with a decrease in stress levels were: having more time for relaxation $(r=-0.40)$, feeling relieved by the reduction of professional/school obligations $(r=-0.33)$, feeling relieved by the reduction of private obligations $(r=-0.29)$, and feeling good to spend more time with family/partner/child(ren) $(r=-0.17)$.

\section{Relation to depressive symptoms (total score PHQ-9)}

The change in stress levels was highly positively correlated with increased depressive symptoms $(r=0.56)$. Stress levels were also positively correlated with cross-sectional depressive scores, both before the pandemic $(r=0.49)$ and during partial deconfinement $(r=0.62)$.

\section{Relation to anxiety levels}

The change in stress levels was highly correlated with change in anxiety levels $(r=$ 0.51). Stress levels were also positively correlated with cross-sectional anxiety levels, both before the pandemic $(r=0.46)$ and during partial deconfinement $(r=0.60)$.

\section{Relation to changeable behaviors during partial deconfinement}

The increase in stress levels was lower in participants who spend more time pursuing other/new projects $(r=-0.17)$ or hobbies at home $(r=-0.17)$, or performing light physical exercise during partial deconfinement $(r=-0.10)$. 


\section{Change in depressive symptoms}

During partial deconfinement, depression scores were increased on average (difference score: mean $=1.57$, median $=0$, sd $=4.63 ;$ before pandemic: mean $=5.24$, median $=4$, $s d=4.71$; during partial deconfinement: mean $=6.8$, median $=5, s d=5.87$, see Figure 5c). $27.1 \%$ of the participants had a lower depression score, $23.4 \%$ had the same score, and $49.5 \%$ of the participants had a higher score during partial deconfinement as compared to the time before the pandemic (see Figure 5c). The proportion of participants who indicated to suffer from at least moderate depressive symptoms (PHQ-9 $\geq 10$ ) before the COVID-19 pandemic was $15.3 \%$. This proportion is higher than the proportion reported for the general population of $8.6 \%$ for the year 2017 (https://www.obsan.admin.ch/de/indikatoren/depressionssymptome). In our study, this proportion raised to $27.2 \%$ for the time of the lockdown. The proportion of all participants suffering from at least moderately severe depression (PHQ-9 score $\geq 15$ ), increased from $5.2 \%$ before the pandemic to $11.7 \%$ during partial deconfinement (Mc Nemar test $p$-value $<2.2 \mathrm{e}-16$; Cohen's $g=0.33$ ). In the matched population (see below), the proportion of all participants suffering from at least moderately severe depression (PHQ-9 score $\geq 15$ ), increased from $4.4 \%$ before the pandemic to $12.5 \%$ during partial deconfinement.

\section{Relation to burdens during partial deconfinement}

The burdens due to the pandemic-related changes (see table 2 for detailed overview) that were most strongly associated with an increase in depression score were: the 
burden of living alone $(r=0.37)$, the burden due to changes at work $(r=0.35)$ or at school $(r=0.34)$, the burden of not being able to spend more time privately with others $(r=0.29)$, the burden due to thoughts about the future $(r=0.29)$, and the burden of not being able to spend more time with others in the working life $(r=0.28)$, the burden of reduced personal freedom $(r=0.26)$, the burden of increased conflicts at home $(r=$ $0.25)$, the burden of childcare for people with children $(r=0.25)$, the burden to keep the two meter security distance $(r=0.22)$.

\section{Relation to reliefs during partial deconfinement}

The reliefs due to the pandemic-related changes that were most strongly associated with a decrease in depression score were: having more time for relaxation $(r=-0.27)$, feeling relieved by the reduction of professional/school obligations $(r=-0.22)$, feeling relieved by the reduction of private obligations $(r=-0.22)$, feeling good to spend more time with family/partner/child(ren) $(r=-0.15)$.

\section{Relation to anxiety levels}

The change in anxiety was highly correlated with change in depression $(r=0.48)$. Anxiety levels were positively correlated with cross-sectional depression scores before the pandemic $(r=0.46)$ and during partial deconfinement $(r=0.58)$.

\section{Relation to changeable behaviors during partial deconfinement}

The increase in depression score was higher in participants who changed their sleep schedule $(r=0.22)$ or eating schedule $(r=0.21)$. In contrast, the increase in depression score was lower in participants who were able to increasingly pursue hobbies at home $(r$ 
$=-0.15)$ or pursue other/new projects $(r=-0.14)$, and perform more light physical activity during lock-down $(r=-0.11)$.

Changes in anxiety levels

During partial deconfinement, anxiety levels increased on average (difference score: mean $=0.55$, median $=0, s d=1.53 ;$ before the pandemic: mean $=1.04$, median $=1$, $S D=1.32 ;$ during the pandemic: mean $=1.59$, median $=1, S D=1.59) \cdot 16 \%$ of participants felt less anxiety, $43.3 \%$ felt the same amount of anxiety, and $40.8 \%$ of participants were more anxious during the partial deconfinement than before the pandemic.

\section{Relation to burdens during partial deconfinement}

The burdens due to the pandemic-related changes that were associated with increased anxiety levels were: the burden of thoughts of the future $(r=0.28)$, burden of living alone $(r=0.28)$, burden of change at work $(r=0.26)$ or at school $(r=0.22)$, fear to get seriously ill by the virus $(r=0.21)$, the burden of not being able to spend more time privately with others $(r=0.19)$, fear of dying of the virus $(r=0.19)$, fear that a close person get seriously ill $(r=0.16)$ or die because of the virus $(r=0.16)$.

\section{Relation to reliefs during partial deconfinement}

The reliefs due to the pandemic-related changes that were most strongly associated with a decrease in anxiety levels were: having more time for relaxation $(r=-0.17)$, feeling relieved by the reduction of professional/school obligations $(r=-0.15)$, feeling relieved by the reduction of private obligations $(r=-0.12)$. 


\section{Relation to changeable behaviors during partial deconfinement}

An increase in anxiety level was higher in participants who did inform themselves more frequently about coronavirus news $(r=0.12)$, changed their sleep schedule $(r=0.12)$, or maintained social contacts by increasingly using smartphones / computers / telephones $(r=0.10)$.

\section{Comparison of wave 1 and wave 2}

\section{Socio-demographic characteristics}

Participants between the two recruitment waves significantly differed for socio-demographic characteristics, including age (Cramer's $V=0.19$ ), living canton (Cramer's $\vee=0.23$ ), age of children (Cramer's $V=0.15$ ), working activity (Cramer's $\vee=$ 0.13), education (Cramer's $V=0.12$ ) and household (Cramer's $V=0.10$ ) (see Supplementary Table 1). Hence, wave 1 and wave 2 populations were matched for these characteristics prior to study outcomes comparison between waves (see Methods).

\section{Stress, anxiety, and depressive symptoms}

No relevant differences in reported stress levels or depressive symptoms (neither for the time before the pandemic, the time during the pandemic or the change) were observed between wave 1 and wave 2 (comparison of categorical distributions before/during: Cramer's $\mathrm{V}<0.1$; comparison of delta means: $\mathrm{R} 2<1 \%$ ) suggesting that 
levels of reported stress and depression did not decrease in the second recruitment wave as compared to the first wave (see Figure $5 a$, Figure $5 c$ ). Of note, the two waves did also not differ in terms of the reported prevalence of prior psychiatric disorder (Cramer's $V<0.01$ ) or prior depression (Cramer's $V=0.04$ ). Interestingly, among participants reporting having regular professional psychological support before the pandemic, the proportion of those continuing receiving support during the pandemic decreased in the second wave $(41.2 \%)$ as compared to the first one (54\%) (Cramer's V $=0.13)$.

For anxiety, we observed a significant difference in reported levels during the pandemic between the two waves (Chi-Square $(5)=492.4, \mathrm{p}<2.2 \mathrm{e}-16$, Cramer's $\mathrm{V}=0.15$ for unmatched datasets ; Cramer's $V=0.11$ for matched datasets) (see Figure $5 b$ ), with a higher proportion of participants reporting no anxiety in the second wave (34.6\%) as compared to the first one $(22 \%)$. In line with this finding, we observed a decrease in anxiety-related variables in participants from the second wave ("afraid that soon it will be no longer possible to buy groceries or medication", Cramer's $V=0.21$; "afraid that someone from my close circle could get seriously ill", Cramer's $V=0.2$; "afraid that someone from my close circle could die“, Cramer's $V=0.19$ ) (Supplementary Table 2 and Supplementary Figure 1). 


\section{Perception of governmental restrictions during the pandemic}

We observed a clear shift of assessments of governmental restrictions between the two waves, with participants from the second wave generally assessing restrictions more disproportionate ("regulation of federation", Cramer's $V=0.23$, Supp Figure 3).

None of the other variables showed a difference between populations with Cramer's $V \geq$ 0.1.

\section{Risk factors for the development of clinically-relevant depressive}

\section{symptoms during the pandemic}

A total of $\mathrm{N}=746$ participants $(7.1 \%)$ of wave 1 shifted from a PHQ-9 score $<15$ before the pandemic to a clinically relevant $\mathrm{PHQ}$ score $\geq 15$ during the pandemic (corresponding to 'moderately severe or severe' PHQ category). A similar proportion $(\mathrm{N}=837,8.1 \%)$ of participants shifting to higher $\mathrm{PHQ}$ severity categories was observed in the second wave population. In both waves, these 'vulnerable' participants were more likely to report higher PHQ scores before the pandemic, with notably higher proportions of subjects in 'moderate' severity as compared to all other participants (Wave 1: $32.6 \%$ vs. $6.5 \%$, Wave $2: 34.5 \%$ vs. $13 \%$ ) (Figure 6 ).

In order to identify possible additional risk factors underlying such an increase in depressive symptoms, we first compared vulnerable participants to all remaining 
participants in terms of socio-demographic characteristics and medical history. This analysis revealed that vulnerable subjects reported higher prevalence of a prior psychiatric disorder as compared to all other participants (wave 1: $50 \%$ vs. $21.6 \%$, Cramer's V $=0.17$; wave $2: 43.2 \%$ vs. $23.1 \%$, Cramer's V $=0.13$ ) (Supplementary Table 3). Notably, vulnerable participants reported higher prevalence of depression and anxiety disorders (Supplementary Table 3). No additional risk factor with at least small effect size (Cramer's $V \geq 0.1$ ) was identified (Supplementary Table 3). Using logistic regression, we observed more 'vulnerable' subjects among participants reporting history of prior psychiatric disorder (Wave 1: $\mathrm{OR}=3.6,95 \% \mathrm{Cl}[3.1-4.2]$; Wave 2: $\mathrm{OR}=2.5$, $95 \% \mathrm{Cl}[2.2-2.9])$.

\section{Resilience factors with regard to depressive symptoms}

A total of $\mathrm{N}=3$ '824 participants $(36.5 \%)$ of wave 1 reported 'none or minimal' depressive symptoms (PHQ score $\leq 4)$ both before and during the pandemic. A similar proportion of participants remaining in the 'none or minimal'-category during the pandemic was observed in wave $2(\mathrm{~N}=3$ '704 participants, $36 \%)$. In order to identify resilience factors, we compared this group to the remaining participants.

In terms of socio-demographic characteristics and medical history, we observed significantly different distributions of age groups (Wave 1: Cramer's $V=0.19$; Wave 2: Cramer's $V=0.26$ ), gender (Wave 1: Cramer's $V=0.15$; Wave 2: Cramer's $V=0.12$ ), profession (Wave 1: Cramer's $V=0.15$; Wave 2: Cramer's $\vee=0.21$ ), as well as report 
of prior psychiatric disorder (Wave 1: Cramer's $V=0.25$; Wave 2: Cramer's $V=0.26$ ) (Supplementary Table 4).

The joint effect of these factors was subsequently examined under a logistic regression framework. This analysis revealed significant effect of age, sex, and prior psychiatric disorder, while the effect of profession on resilience was largely diminished when accounting for the other factors (Nagelkerke pseudo-R2 $<1 \%$ ).

Specifically, logistic regression indicated higher resilience frequency among participants not reporting prior psychiatric disorder (wave 1 and wave 2: OR $=4.3$ ) (Table 3), Figure 7a). We also observed significantly higher resilience rates among older age groups '55-64' and '>=65' year old (Wave 1: OR $=1.7$ and 3.8 respectively as compared to age group '35-44'; Wave $2=1.9$ and 2.8 respectively) (Table 3, Figure 7b).

In addition, higher frequency of resilient participants were observed among males (Wave 1: OR = 1.8; Wave 2: OR = 1.6) $($ Table 3, Figure 7c).

Of note, 'resilient' subjects represent a majority of subjects having PHQ score $\leq 4$ during the pandemic (wave 1: 84.3\%; wave 2: 83.2\%). Consistently, we observed comparable effects of age, sex and prior psychiatric risk on the probability to show a PHQ score $\leq 4$ before and during the crisis (interaction terms of each factor with pandemic, Nagelkerke pseudo-R2 < 0.1\%) (Supplementary Figure 3a-c). 


\section{Summary of results and conclusion}

Wave 1: In this first stage of data analysis, we focused on changes in stress levels due to the pandemic and the confinement. Specifically, we compared stress levels rated for the 2nd and 3rd week of the confinement, with those rated for the time before the COVID-19 pandemic (first two weeks of February 2020).

This analysis was based on data collected with an online questionnaire at a single point in time. In order to protect the anonymity of the participants and to be able to obtain a quick "snapshot" of the effects of the current situation on the Swiss population, we did not aim to collect a representative sample of the population, but rather relied on collecting self-reported data by volunteers responding to our call for participants in the press. Nonetheless, we collected data from a large population with a substantial heterogeneity in sociodemographic characteristics.

While roughly one quarter of participants noted no change in stress levels, half of the participants reported an increase in stress levels during confinement. We identified several potential sources for people feeling more stressed during confinement, such as the burden related to changes at work or school, problems with childcare or burden of not being able to spend more time with others.

Interestingly, one quarter of participants showed a decrease in stress levels, suggesting that for those individuals the lockdown involved a reduction of stressors and/or resulted in more time for recovery. 
The changes in stress levels were highly correlated with changes in depressive symptoms. $57 \%$ of the participants reported an increase in depressive symptoms. Further, the prevalence of moderately severe or severe depression (PHQ-9 score $\geq 15$ ) raised from $3.4 \%$ (before the COVID-19 pandemic) to $9.1 \%$ (during confinement).

Finally, we identified several behaviors amenable to change that were related to the lockdown-induced increase in stress levels and depressive symptoms. It is important to note that the relationships found do not inform us about causality or direction of causality. For some factors, such as engaging in physical exercise, interventional studies have provided evidence for a protective effect with regard to stress and depression [7]. However, it was unknown if they are also effective in the situation of a pandemic lockdown. In the present study, we provide evidence for some of those factors being related to a smaller increase in stress levels during confinement, in particular engaging in physical exercise.

Wave 2: In the phase of partial deconfinement we found a similar pattern of reactions with regard to stress and depressive symptoms. In contrast, anxiety levels decreased from wave 1 to wave 2 . The burdens and reliefs related to stress changes were similar across waves. With regard to changeable behaviors during the pandemic, we again found that spending more time pursuing new projects, spending more time pursuing hobbies at home, and light physical exercise were related to less stress increase. In contrast, intense physical exercise and corona news consumption were no longer related at the defined effect size level. 
In both waves, we identified a history of prior psychiatric disorder as a risk factor for the development of clinically-relevant depressive symptoms during the pandemic. Further, we identified advanced age ( $\geq 55$ years) and male gender as factors of resilience (i.e. having no or only minor depressive symptoms before as well as during the pandemic), while individuals with a history of prior psychiatric disorder are less likely to be in this resilient group. 


\section{Figures}

Figure 1: distribution of stress levels before and during confinement.

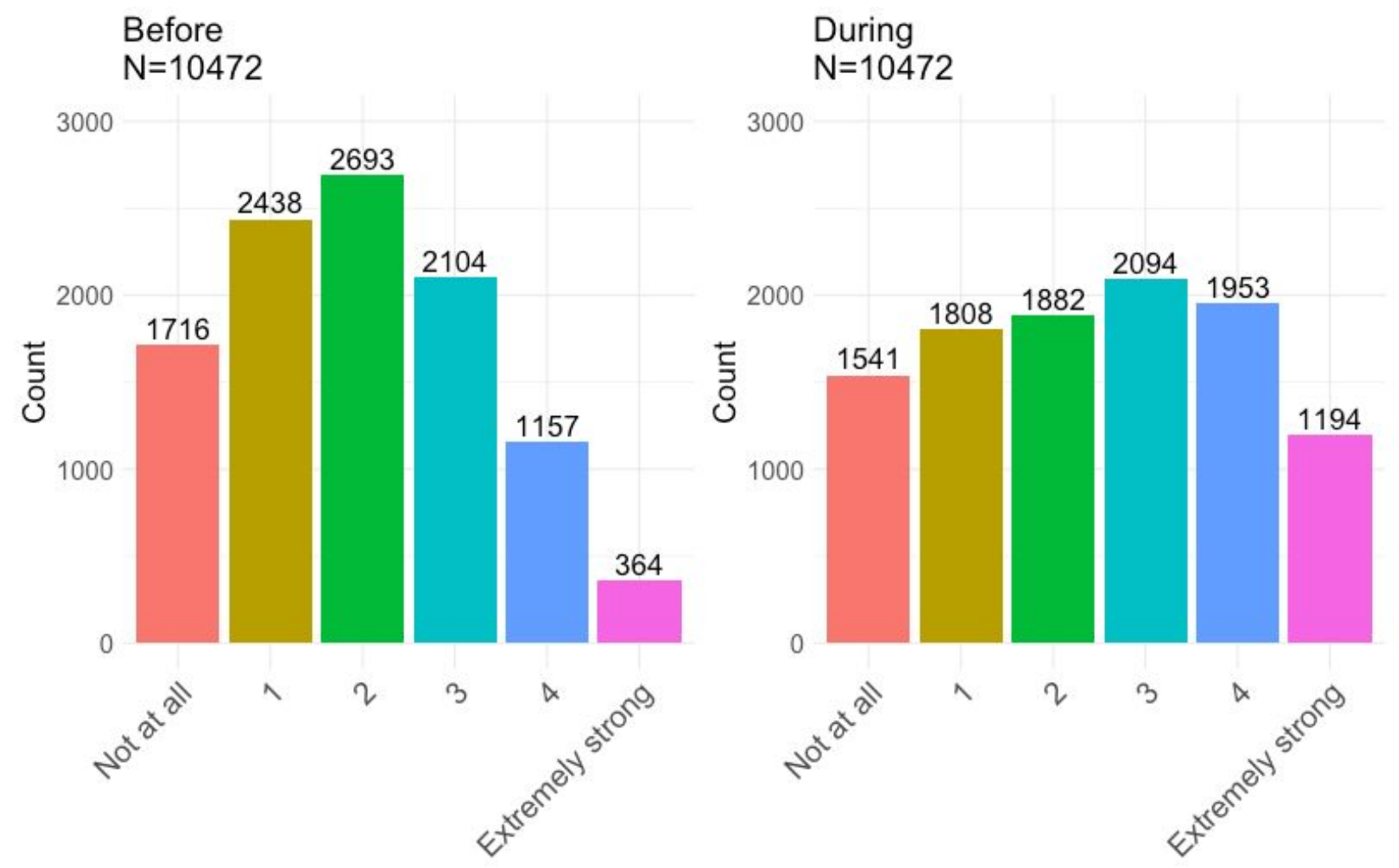


Figure 2a: distribution of change in stress level.

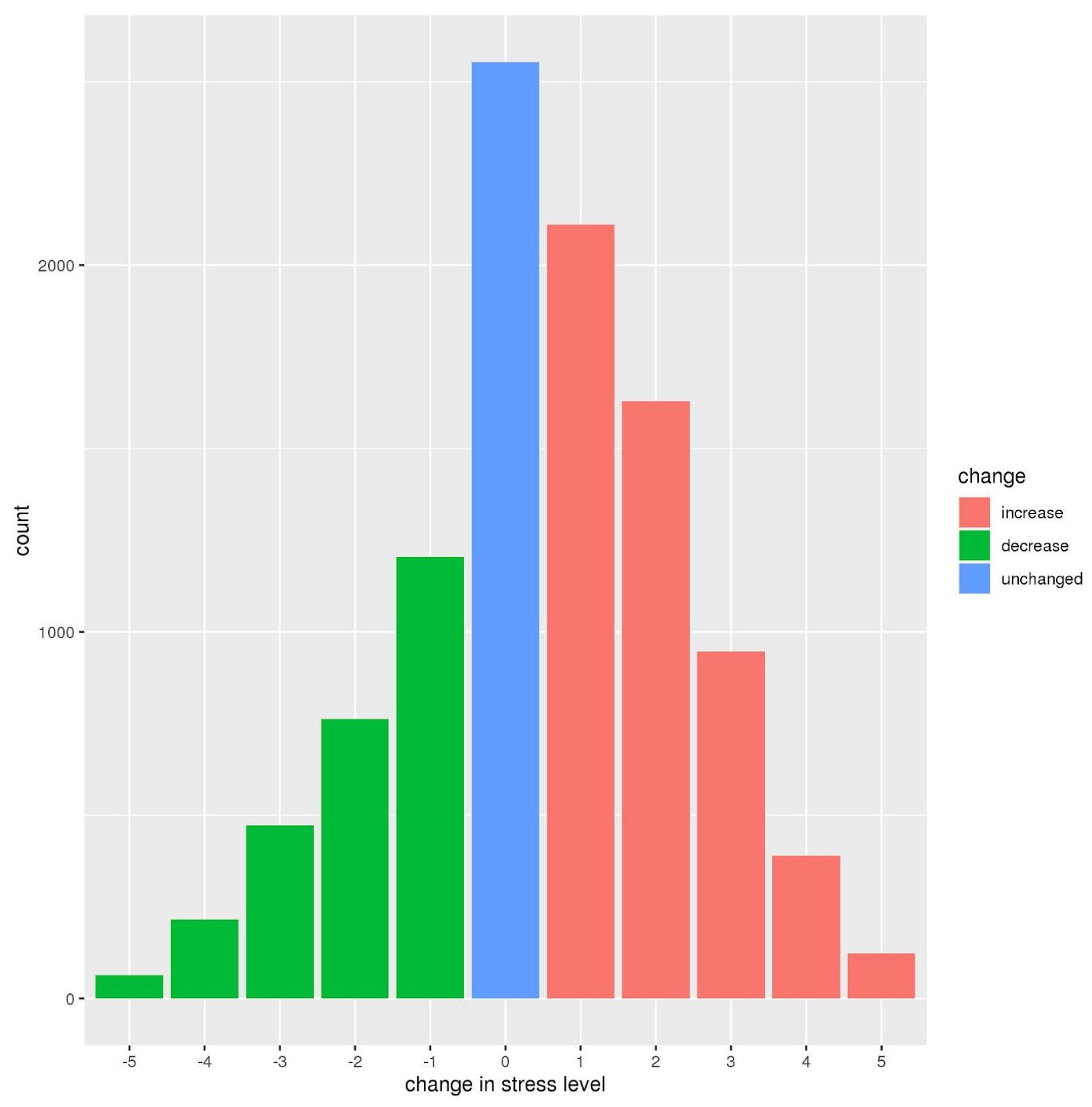


Figure 2b : Distribution of change in stress levels by levels of stress before pandemic.

Counts $<100$ not shown.

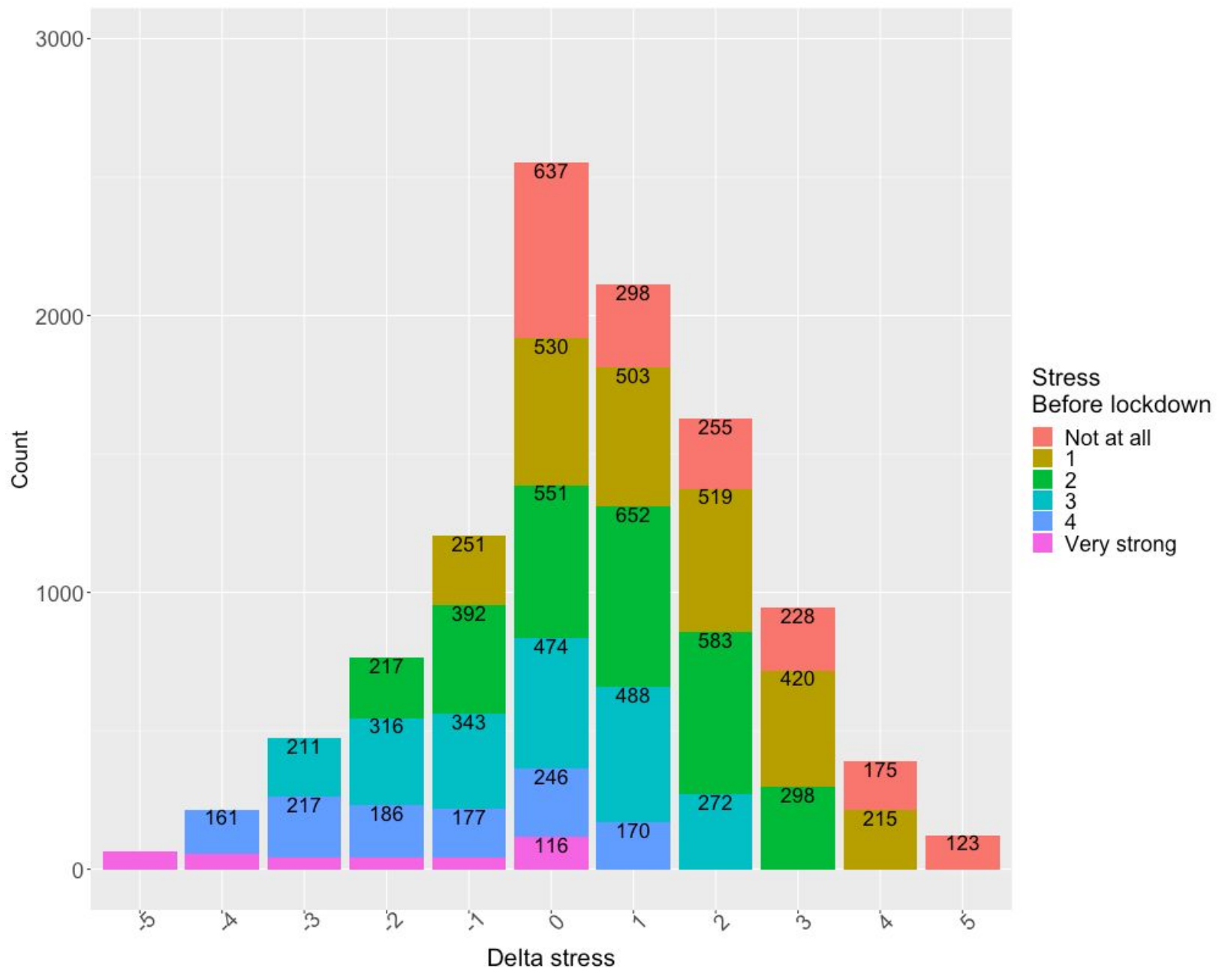


Figure 3: distribution of depression scores before and during confinement.
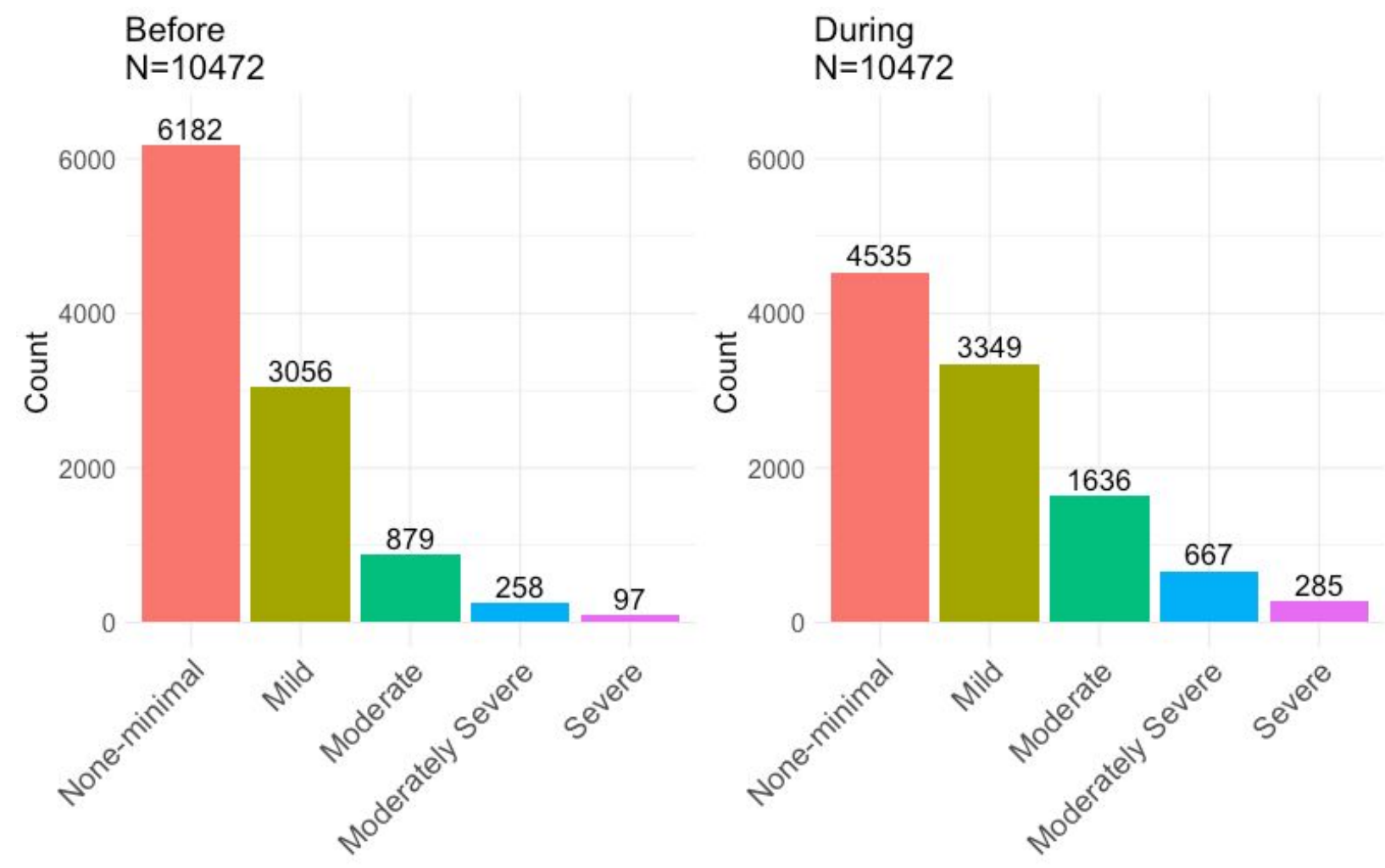

PHQ-score categories: None-minimal [0-5[; Mild [5-10[; Moderate [10-15[; Moderately severe [15-20[ ; Severe $\geq 20$. 
Figure 4: distribution of change in depression score.

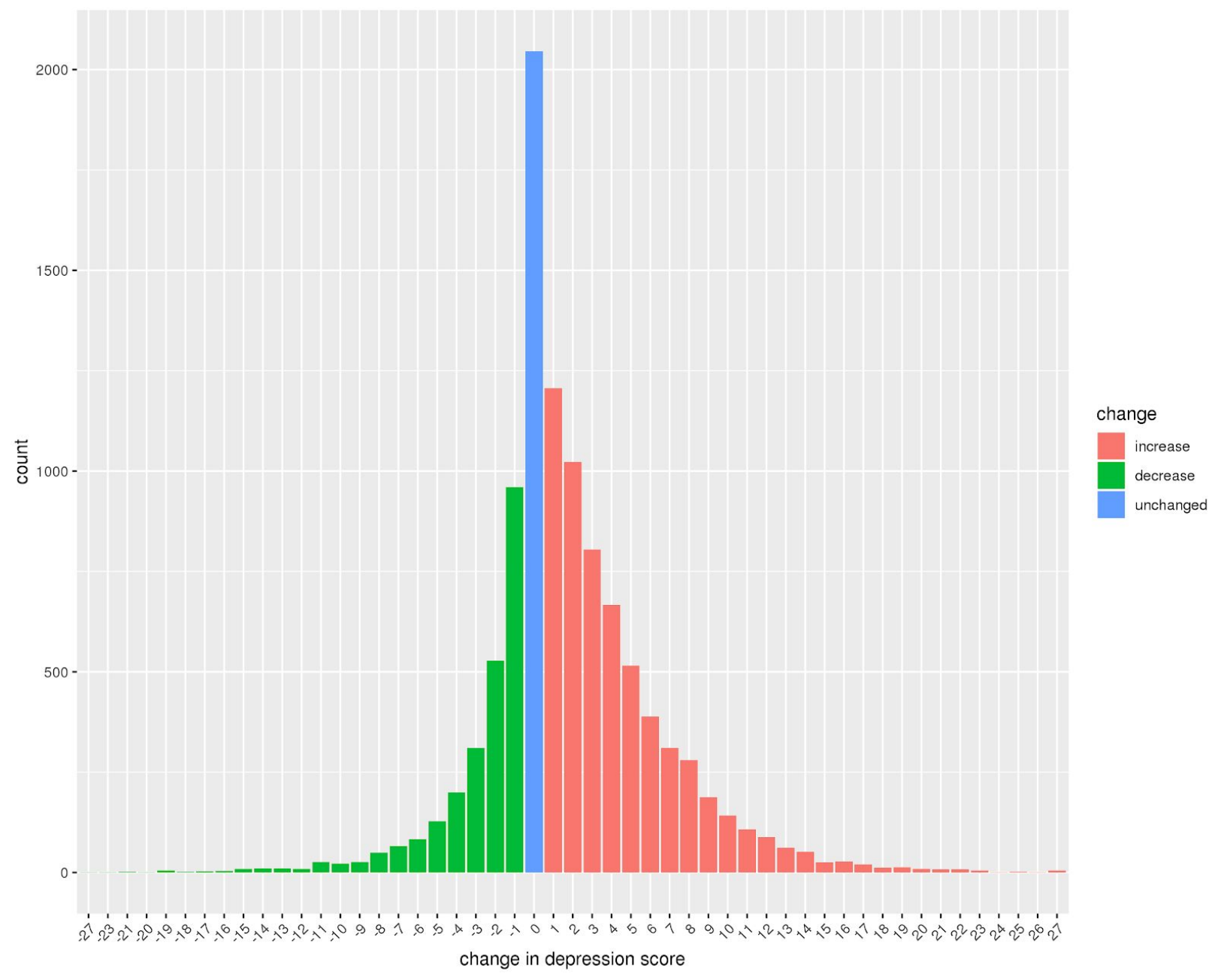


Figure 5a: Comparison of stress levels between Wave 1 and Wave 2.

Comparison on unmatched data.

Proportion: proportion of participants within a category, relative to the total number of participants in a given wave.

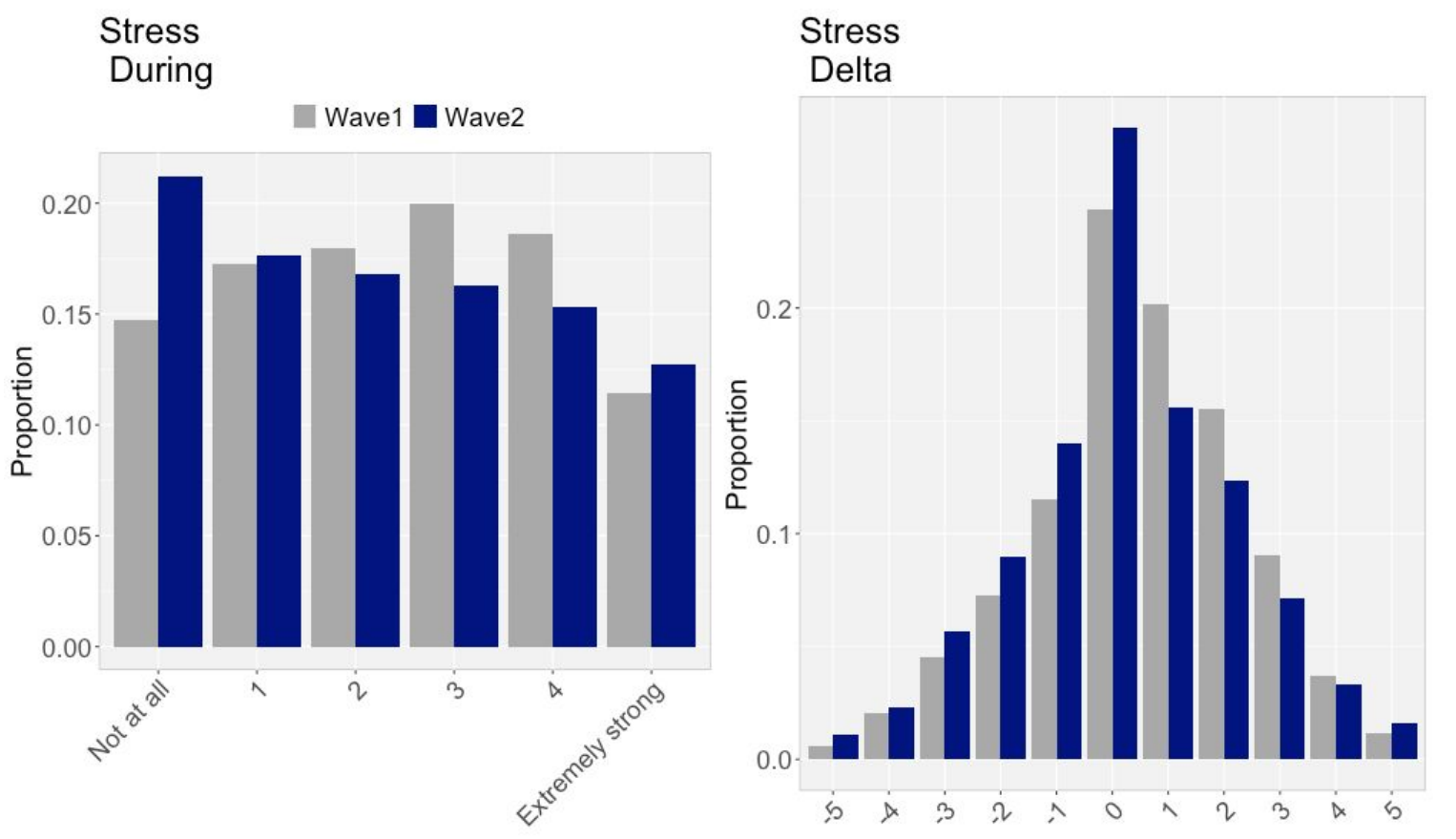


Figure 5b: Comparison of anxiety levels between Wave 1 and Wave 2.

Comparison on unmatched data.

Proportion: proportion of participants within a category, relative to the total number of participants in a given wave.
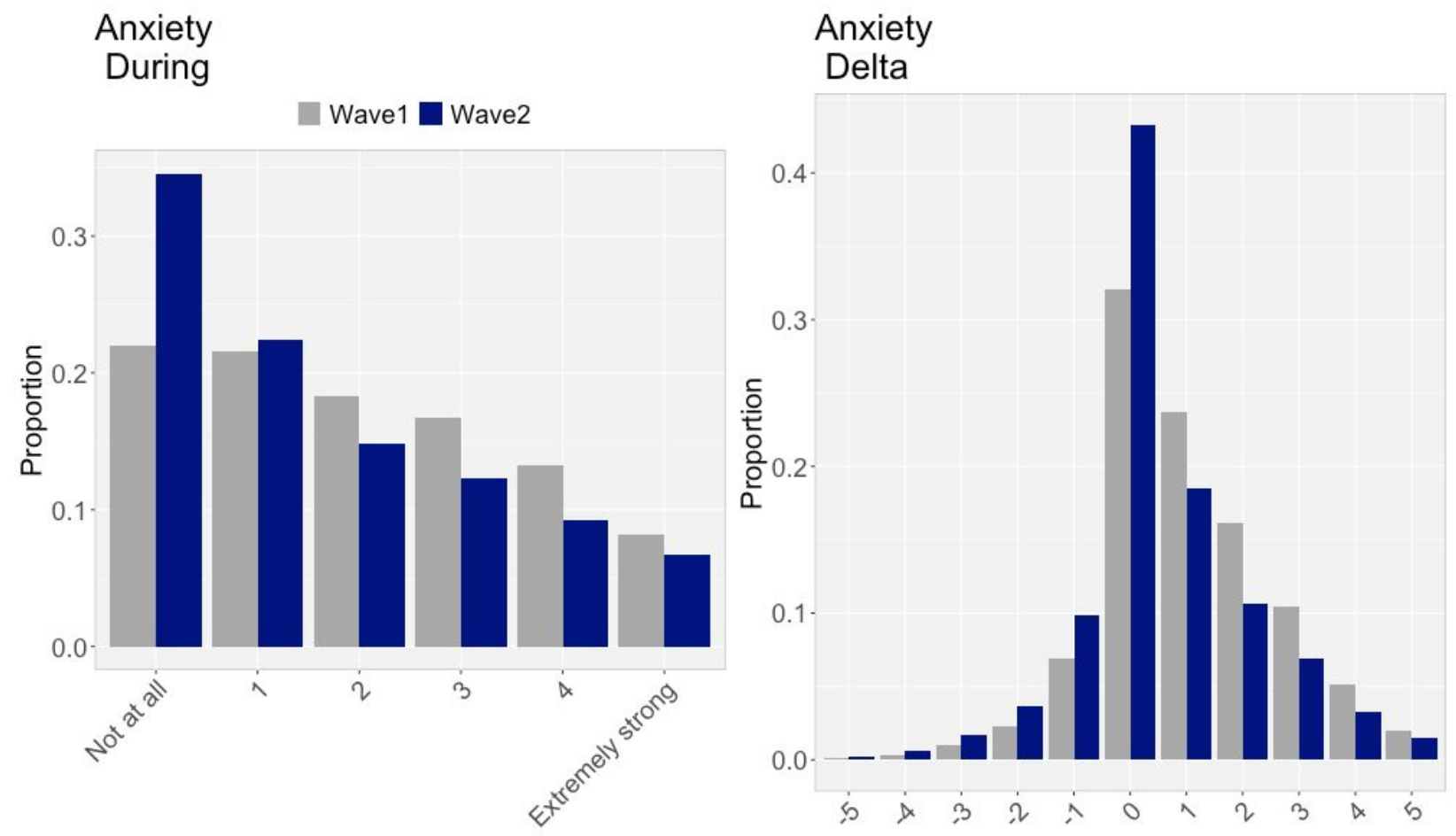
Figure 5c: Comparison of depressive symptoms between Wave 1 and Wave 2.

Comparison on unmatched data.

Proportion: proportion of participants within a category, relative to the total number of participants in a given wave.
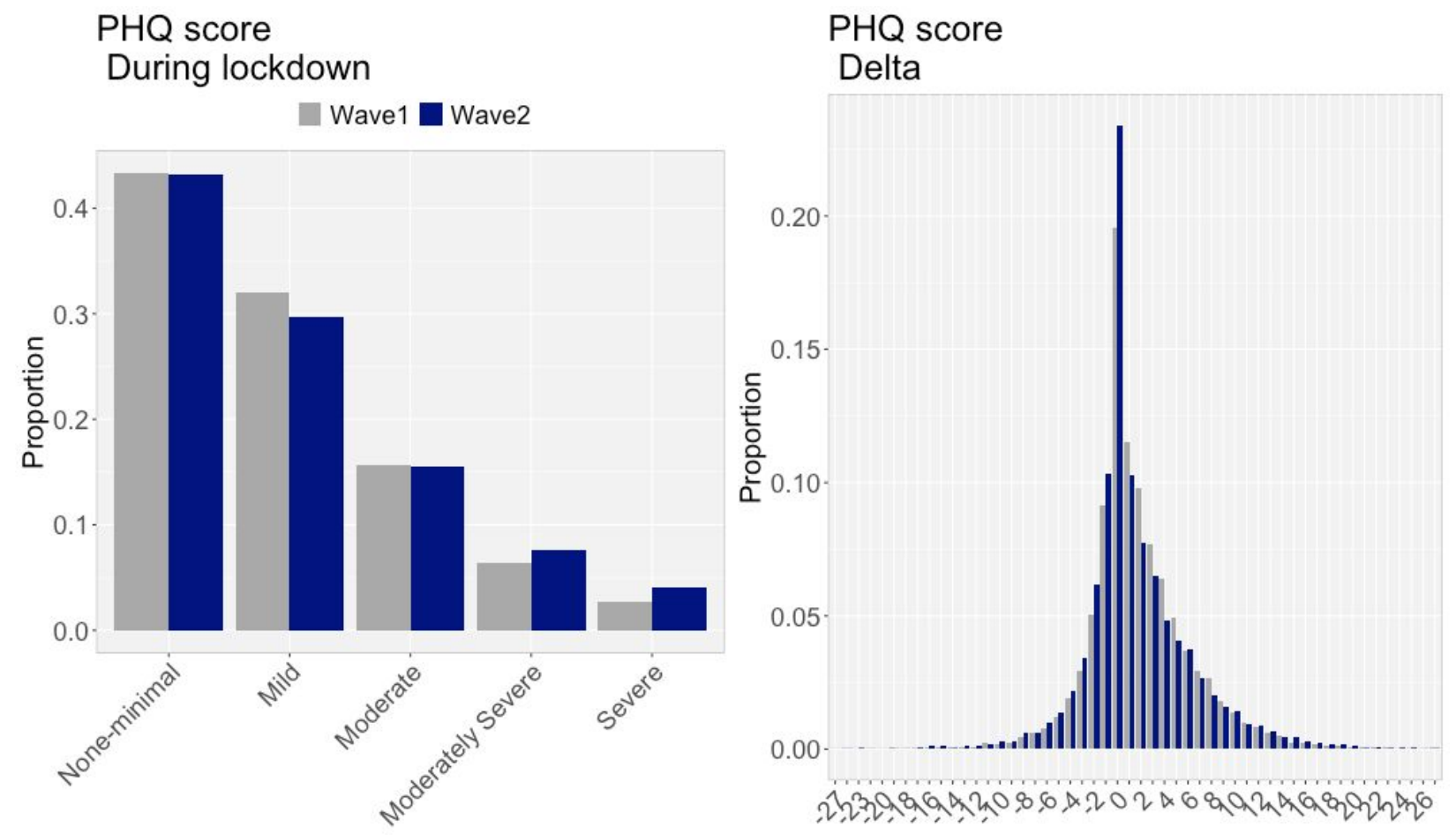
Figure 6: Distribution of $\mathrm{PHQ}$ categories before pandemic in vulnerable subjects.

Left panel: Wave1. Right panel: Wave2. Percentage: refers to the percentage of participants within each category relative to the total number of subjects within a group (Other or Vulnerable).

Wave1

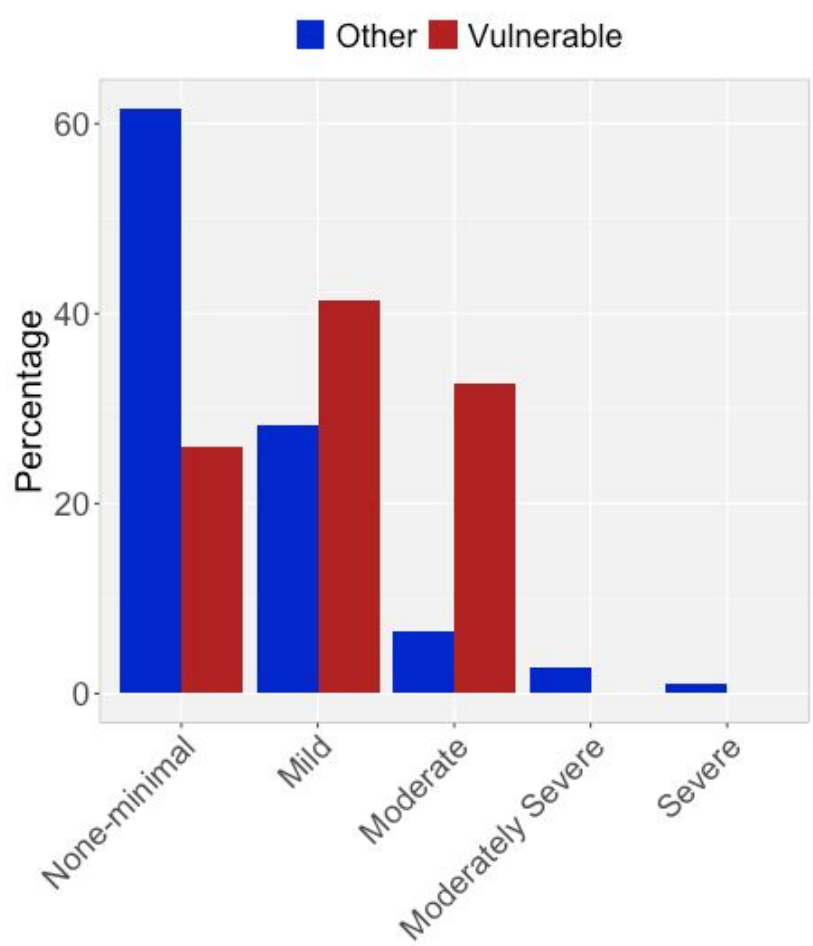

Wave2

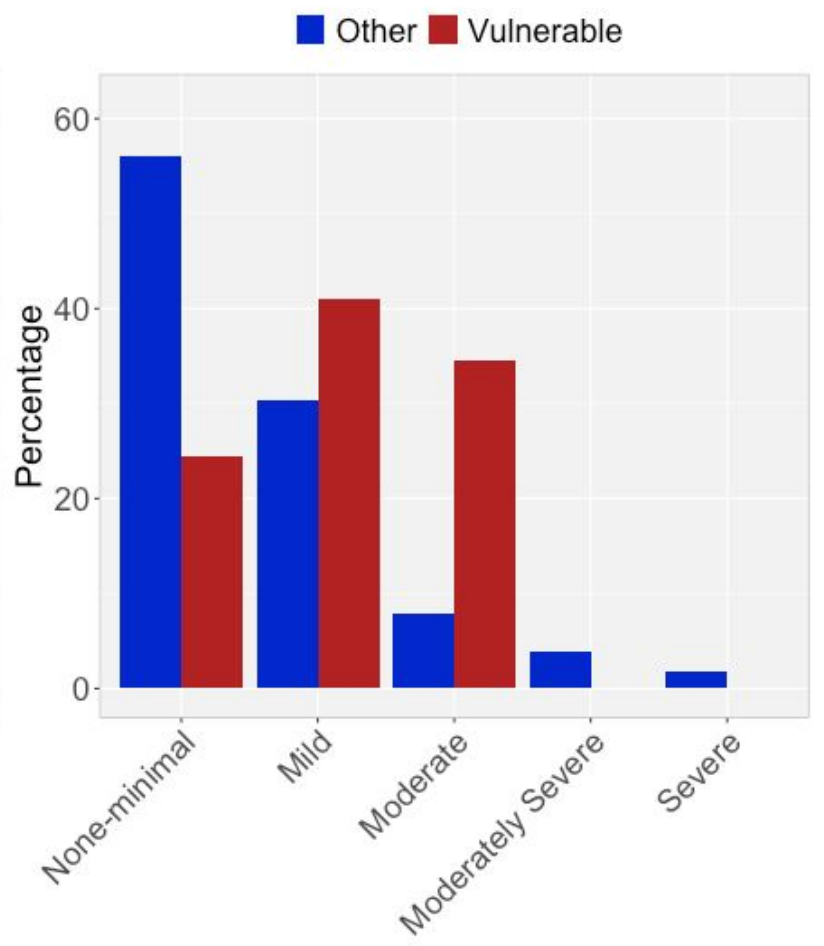

PHQ groups (before) 
Figure 7a: Resilience rates by history of prior psychiatric disorder.

Plot of marginal effects estimated from Logit regression model on 'resilience'. Error bars represent $95 \%$ confidence intervals.

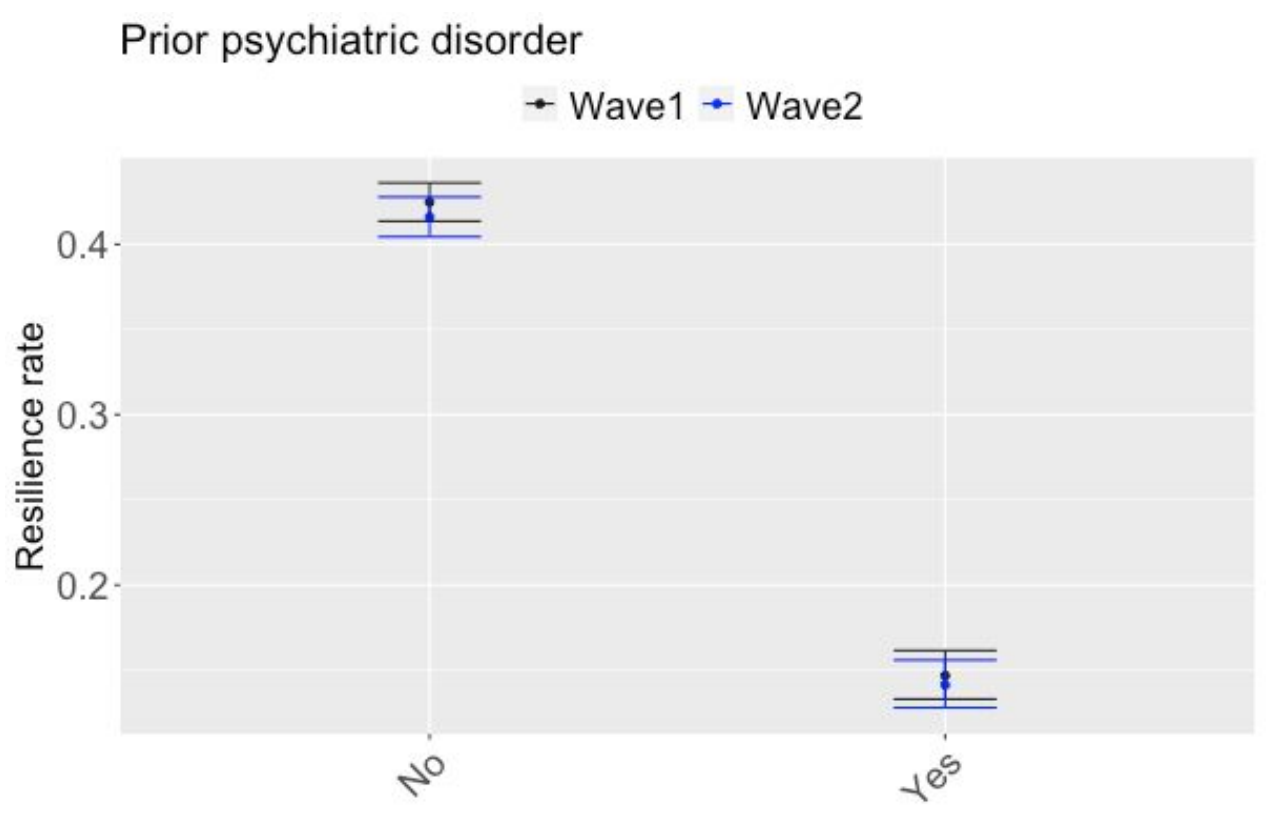


Figure 7b: Resilience rates by age group.

Plot of marginal effects estimated from Logit regression model on 'resilience'. Error bars represent $95 \%$ confidence intervals.

Age

$$
\text { - Wave1 - Wave2 }
$$

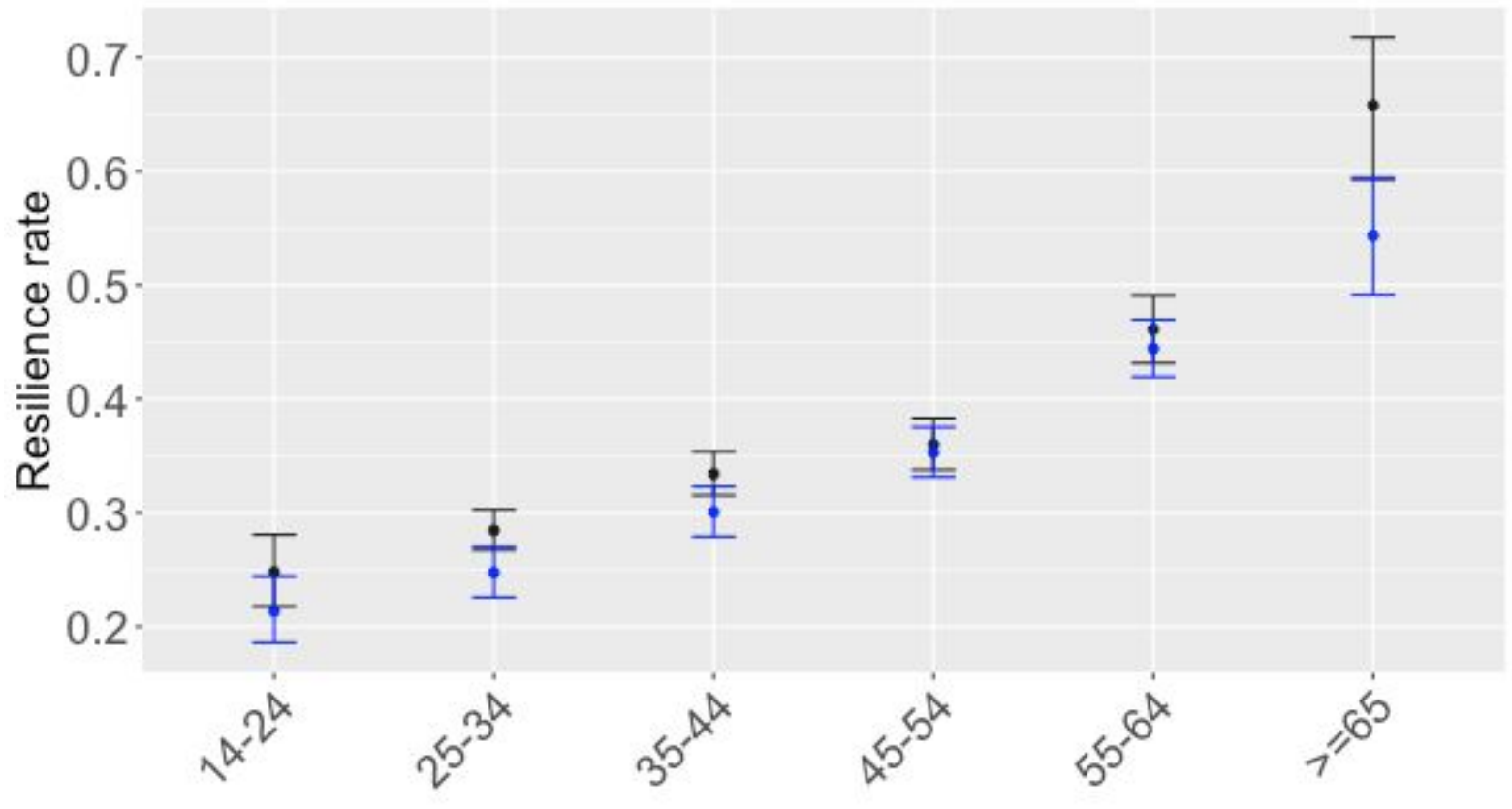


Figure 7c: Resilience rates by gender.

Plot of marginal effects estimated from Logit regression model on 'resilience'. Error bars represent $95 \%$ confidence intervals.

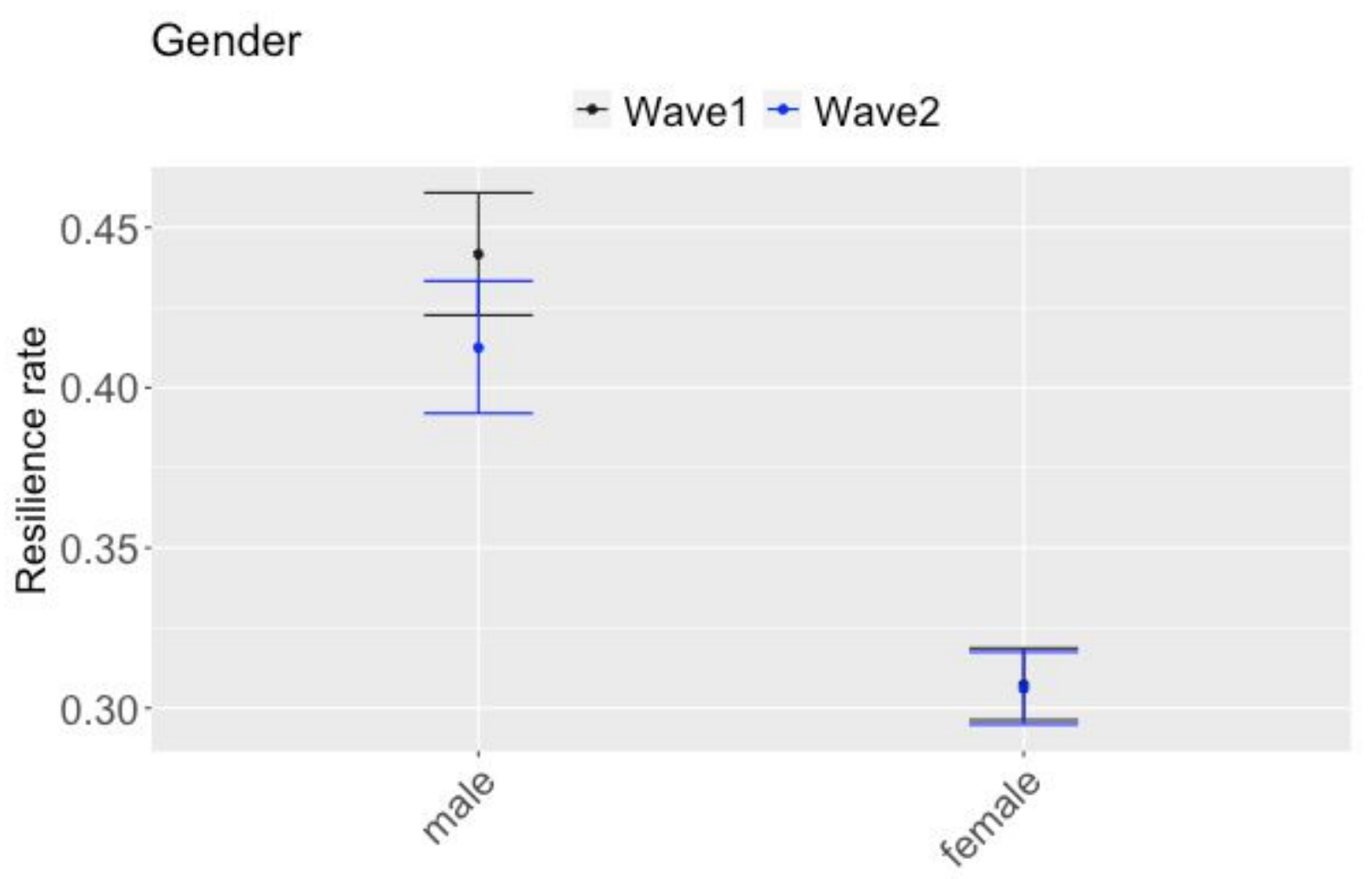




\section{Tables}

\section{Table1: Stress, depression and anxiety changes in relation to burdens during confinement $(|r| \geq 0.1)$.}

\begin{tabular}{|c|c|c|c|c|}
\hline Rank & Variable & $\mathrm{N}$ & r & $\mathrm{p}$ \\
\hline \multicolumn{5}{|c|}{ Stress level } \\
\hline 1 & feeling relieved in the actual situation & 5917 & -0.50 & $2.1 e-107$ \\
\hline 2 & burden due to changes at school & 1455 & 0.39 & $1.2 e-52$ \\
\hline 3 & burden due to changes at work & 7374 & 0.37 & $5.4 e-233$ \\
\hline 4 & confidence to overcome this crisis well & 10472 & -0.32 & $1.6 e-243$ \\
\hline 5 & burden of childcare & 2333 & 0.30 & $8.5 e-49$ \\
\hline 6 & burden of living alone & 2078 & 0.30 & $1.4 \mathrm{e}-43$ \\
\hline 7 & burden due to thoughts about the future & 5776 & 0.27 & $1.5 e-100$ \\
\hline 8 & $\begin{array}{l}\text { burden of not being able to spend more } \\
\text { time privately with others }\end{array}$ & 10472 & 0.25 & $5.0 e-152$ \\
\hline 9 & burden of reduced personal freedom & 10472 & 0.23 & $1.5 e-122$ \\
\hline 10 & $\begin{array}{l}\text { being overwhelmed by the switch to digital } \\
\text { media/class/teaching }\end{array}$ & 10472 & 0.20 & $3.9 e-99$ \\
\hline 11 & $\begin{array}{l}\text { burden to keep to the 2-meter security } \\
\text { distance }\end{array}$ & 10472 & 0.19 & $9.2 \mathrm{e}-89$ \\
\hline 12 & increase of conflicts at home & 8396 & 0.19 & $2.8 e-71$ \\
\hline 13 & $\begin{array}{l}\text { burden of not being able to spend more } \\
\text { time with others in my working life }\end{array}$ & 10472 & 0.18 & $5.0 e-79$ \\
\hline
\end{tabular}




\begin{tabular}{lllll}
\hline 14 & $\begin{array}{l}\text { fear of getting seriously ill with the } \\
\text { coronavirus }\end{array}$ & 10472 & 0.17 & $3.0 \mathrm{e}-67$ \\
\hline 15 & fear of dying from the coronavirus & 10472 & 0.17 & $3.9 \mathrm{e}-66$ \\
\hline 16 & burden of financial consequences & 10472 & 0.16 & $2.2 \mathrm{e}-60$ \\
\hline 17 & $\begin{array}{l}\text { It feels good to spend more time with my } \\
\text { family/partner/child(ren) }\end{array}$ & 10472 & -0.15 & $5.3 \mathrm{e}-55$ \\
\hline 18 & $\begin{array}{l}\text { burden to forego cultural events and visits } \\
\text { (museum, theater, concerts) }\end{array}$ & 10472 & 0.15 & $1.3 \mathrm{e}-51$ \\
\hline 19 & $\begin{array}{l}\text { fear that soon it will no longer be possible } \\
\text { to buy groceries or medication }\end{array}$ & 10472 & 0.13 & $4.6 \mathrm{e}-39$ \\
\hline 20 & $\begin{array}{l}\text { I have to/can work more/less in the current } \\
\text { situation. }\end{array}$ & 10472 & 0.13 & $7.4 \mathrm{e}-39$ \\
\hline 21 & $\begin{array}{l}\text { fear that someone from my closest circle could } \\
\text { die from the coronavirus }\end{array}$ & 10472 & 0.13 & $1.3 \mathrm{e}-38$ \\
\hline 22 & $\begin{array}{l}\text { fear that someone from my closest circle } \\
\text { could get seriously ill with the coronavirus }\end{array}$ & & & \\
\hline
\end{tabular}

\section{Depression score}

\begin{tabular}{lllll}
\hline 1 & feeling relieved in the actual situation & 5917 & -0.42 & $3.2 \mathrm{e}-246$ \\
\hline 2 & burden of living alone & 2078 & 0.42 & $2.3 \mathrm{e}-87$ \\
\hline 3 & burden due to changes at work & 7374 & 0.37 & $3.0 \mathrm{e}-243$ \\
\hline 4 & burden due to changes at school & 1455 & 0.37 & $5.8 \mathrm{e}-49$ \\
\hline 5 & confidence to overcome the crisis well & 10472 & -0.35 & $6.2 \mathrm{e}-293$ \\
\hline 6 & burden due to thoughts about the future & 5776 & 0.33 & $5.6 \mathrm{e}-144$ \\
\hline 7 & $\begin{array}{l}\text { burden of not being able to spend more } \\
\text { time privately with others }\end{array}$ & & 0.31 & $4.5 \mathrm{e}-236$ \\
\hline 8 & burden of reduced personal freedom & 10472 & 0.29 & $9.4 \mathrm{e}-198$ \\
\hline 9 & burden of childcare & 2333 & 0.28 & $1.8 \mathrm{e}-42$ \\
\hline
\end{tabular}




\begin{tabular}{|c|c|c|c|c|}
\hline 10 & $\begin{array}{l}\text { burden of not being able to spend more } \\
\text { time with others in my working life }\end{array}$ & 10472 & 0.28 & $1.7 e-181$ \\
\hline 11 & increase of conflicts at home & 8396 & 0.26 & $4.8 e-126$ \\
\hline 12 & $\begin{array}{l}\text { being overwhelmed by the switch to digital } \\
\text { media/class/teaching }\end{array}$ & 10472 & 0.23 & $5.3 e-130$ \\
\hline 13 & $\begin{array}{l}\text { burden to keep to the 2-meter security } \\
\text { distance }\end{array}$ & 10472 & 0.22 & $6.8 e-116$ \\
\hline 14 & burden of financial consequences & 10472 & 0.21 & $1.3 e-107$ \\
\hline 15 & $\begin{array}{l}\text { burden to forego cultural events and visits } \\
\text { (museum, theater, concerts) }\end{array}$ & 10472 & 0.20 & $2.3 e-98$ \\
\hline 16 & $\begin{array}{l}\text { It feels good to spend more time with my } \\
\text { family/partner/child(ren) }\end{array}$ & 10472 & -0.17 & $1.2 e-68$ \\
\hline 17 & $\begin{array}{l}\text { fear that soon it will no longer be possible } \\
\text { to buy groceries or medication }\end{array}$ & 10472 & 0.15 & $1.5 e-53$ \\
\hline 18 & $\begin{array}{l}\text { fear of getting seriously ill with the } \\
\text { coronavirus }\end{array}$ & 10472 & 0.15 & $2.2 e-52$ \\
\hline 19 & fear of dying from the coronavirus & 10472 & 0.14 & $1.9 e-48$ \\
\hline 20 & $\begin{array}{l}\text { fear that someone from my closest circle } \\
\text { could die from the coronavirus }\end{array}$ & 10472 & 0.13 & $2.8 e-43$ \\
\hline 21 & $\begin{array}{l}\text { fear that someone from my closest circle } \\
\text { could get seriously ill with the coronavirus }\end{array}$ & 10472 & 0.13 & $3.2 \mathrm{e}-40$ \\
\hline 22 & increasingly exposed to domestic violence & 10472 & 0.13 & $2.9 e-38$ \\
\hline
\end{tabular}

\begin{tabular}{lllll}
\hline \multicolumn{4}{l}{ Anxiety level } \\
\hline 1 & burden due to thoughts about the future & 5776 & 0.35 & $1.9 \mathrm{e}-168$ \\
\hline 2 & confidence to overcome the crisis well & 10472 & -0.35 & $4.7 \mathrm{e}-298$ \\
\hline 3 & getting infected of the virus & 10472 & 0.32 & $3.5 \mathrm{e}-245$ \\
\hline 4 & burden of living alone & 2078 & 0.31 & $1.8 \mathrm{e}-47$ \\
\hline
\end{tabular}




\begin{tabular}{|c|c|c|c|c|}
\hline 5 & burden due to changes at work & 7374 & 0.31 & $5.5 e-160$ \\
\hline 6 & dying because of the virus & 10472 & 0.29 & $1.0 e-203$ \\
\hline 7 & $\begin{array}{l}\text { feeling relieved by the absence of private } \\
\text { obligations }\end{array}$ & 5917 & -0.27 & $6.4 e-100$ \\
\hline 8 & burden due to changes at school & 1455 & 0.26 & $4.4 \mathrm{e}-24$ \\
\hline 9 & fear that a close person die because of virus & 10472 & 0.26 & $9.7 e-156$ \\
\hline 10 & $\begin{array}{l}\text { fear that a close person get infected by the } \\
\text { virus }\end{array}$ & 10472 & 0.25 & $3.0 e-151$ \\
\hline 11 & $\begin{array}{l}\text { burden of not being able to spend more time } \\
\text { privately with others }\end{array}$ & 10472 & 0.21 & $1.5 e-103$ \\
\hline 12 & burden of financial consequences & 10472 & 0.2 & $8.5 e-98$ \\
\hline 13 & $\begin{array}{l}\text { the burden to keep the two meter security } \\
\text { distance }\end{array}$ & 10472 & 0.2 & $9.6 e-91$ \\
\hline 14 & the burden of reduced personal freedom & 10472 & 0.18 & $1.2 \mathrm{e}-78$ \\
\hline 15 & $\begin{array}{l}\text { being afraid that soon it will no longer be } \\
\text { possible to buy groceries or medication }\end{array}$ & 10472 & 0.17 & $7.5 e-69$ \\
\hline 16 & $\begin{array}{l}\text { burden of not being able to spend more time } \\
\text { with others in my working life }\end{array}$ & 10472 & 0.16 & $1.3 e-62$ \\
\hline 17 & $\begin{array}{l}\text { being overwhelmed by the switch to digita } \\
\text { media/class/teaching }\end{array}$ & 10472 & 0.16 & $4.7 e-61$ \\
\hline 18 & increased conflicts at home & 8396 & 0.13 & $9.5 e-33$ \\
\hline 19 & $\begin{array}{l}\text { the burden of childcare for people with } \\
\text { children }\end{array}$ & 2333 & 0.12 & $2.0 e-08$ \\
\hline 20 & burden to forego cultural events and visits & 10472 & 0.11 & $6.8 e-30$ \\
\hline
\end{tabular}




\section{Table2: Stress, depression and anxiety changes in relation to burdens during deconfinement $(|r| \geq 0.1)$.}

\begin{tabular}{|c|c|c|c|c|}
\hline Rank & Variable & $\mathrm{N}$ & $r$ & $\mathrm{p}$ \\
\hline \multicolumn{5}{|c|}{ Stress level } \\
\hline 1 & having more time for relaxation & 10303 & -0.40 & $<2.2 \mathrm{e}-16$ \\
\hline 2 & burden due to changes at school & 1582 & 0.35 & $1.88 e-45$ \\
\hline 3 & burden due to changes at work & 6457 & 0.34 & $1.85 e-173$ \\
\hline 4 & $\begin{array}{l}\text { feeling relieved by the absence of } \\
\text { professional / school obligations }\end{array}$ & 10303 & -0.33 & $8.80 \mathrm{e}-259$ \\
\hline 5 & $\begin{array}{l}\text { feeling relieved by the absence of private } \\
\text { obligations }\end{array}$ & 10303 & -0.29 & $9.72 \mathrm{e}-199$ \\
\hline 6 & burden of living alone & 2169 & 0.28 & $1.62 \mathrm{e}-39$ \\
\hline 7 & confidence to overcome the crisis well & 10303 & -0.27 & $6.95 e-168$ \\
\hline 8 & $\begin{array}{l}\text { burden of not being able to spend more } \\
\text { time privately with others }\end{array}$ & 10303 & 0.26 & $1.67 e-161$ \\
\hline 9 & $\begin{array}{l}\text { the burden of childcare for people with } \\
\text { children }\end{array}$ & 2230 & 0.26 & $3.99 e-35$ \\
\hline 10 & burden due to thoughts about the future & 10303 & 0.25 & $1.62 \mathrm{e}-147$ \\
\hline 11 & the burden of reduced personal freedom & 10303 & 0.24 & $2.01 e-131$ \\
\hline 12 & $\begin{array}{l}\text { the burden to keep the two meter security } \\
\text { distance }\end{array}$ & 10303 & 0.20 & $5.15 e-91$ \\
\hline 13 & $\begin{array}{l}\text { burden of not being able to spend more } \\
\text { time with others in my working life }\end{array}$ & 10303 & 0.19 & $2.21 \mathrm{e}-87$ \\
\hline 14 & increased conflicts at home & 8134 & 0.18 & $6.66 e-62$ \\
\hline 15 & $\begin{array}{l}\text { being overwhelmed by the switch to digital } \\
\text { media/class/teaching }\end{array}$ & 10303 & 0.17 & $1.40 \mathrm{e}-66$ \\
\hline
\end{tabular}




\begin{tabular}{lllll}
\hline \multicolumn{1}{c}{$\begin{array}{l}\text { feeling good to spend more time with } \\
\text { family / partner/child(ren) }\end{array}$} & 10303 & -0.17 & $5.06 \mathrm{e}-64$ \\
\hline 17 & burden to forego cultural events and visits & 10303 & 0.16 & $4.78 \mathrm{e}-58$ \\
\hline 18 & $\begin{array}{l}\text { I have to/can work more/less in the current } \\
\text { situation }\end{array}$ & 10303 & 0.14 & $2.35 \mathrm{e}-43$ \\
\hline 19 & burden of financial consequences & 10303 & 0.13 & $4.35 \mathrm{e}-39$ \\
\hline 20 & $\begin{array}{l}\text { I feel I have less/more control on my own } \\
\text { situation }\end{array}$ & 10303 & -0.10 & $8.71 \mathrm{e}-23$ \\
\hline
\end{tabular}

\section{Depression}

\begin{tabular}{|c|c|c|c|c|}
\hline 1 & burden of living alone & 2169 & 0.37 & $2.74 \mathrm{e}-71$ \\
\hline 2 & burden due to changes at school & 1582 & 0.35 & $9.19 e-46$ \\
\hline 3 & burden due to changes at work & 6457 & 0.34 & $2.87 e-171$ \\
\hline 4 & confidence to overcome the crisis well & 10303 & -0.32 & $3.16 e-242$ \\
\hline 5 & $\begin{array}{l}\text { burden of not being able to spend more } \\
\text { time privately with others }\end{array}$ & 10303 & 0.29 & $7.95 e-205$ \\
\hline 6 & burden due to thoughts about the future & 10303 & 0.29 & $1.76 e-196$ \\
\hline 7 & $\begin{array}{l}\text { burden of not being able to spend more } \\
\text { time with others in my working life }\end{array}$ & 10303 & 0.28 & $1.70 \mathrm{e}-178$ \\
\hline 8 & having more time for relaxation & 10303 & -0.27 & $6.08 \mathrm{e}-176$ \\
\hline 9 & the burden of reduced personal freedom & 10303 & 0.26 & $8.55 \mathrm{e}-157$ \\
\hline 10 & increased conflicts at home & 8134 & 0.25 & $2.75 \mathrm{e}-120$ \\
\hline 11 & $\begin{array}{l}\text { the burden of childcare for people with } \\
\text { children }\end{array}$ & 2230 & 0.25 & $6.03 e-34$ \\
\hline 12 & $\begin{array}{l}\text { feeling relieved by the absence of } \\
\text { professional / school obligations }\end{array}$ & 10303 & -0.22 & $2.07 e-113$ \\
\hline 13 & $\begin{array}{l}\text { the burden to keep the two meter security } \\
\text { distance }\end{array}$ & 10303 & 0.22 & $5.03 e-113$ \\
\hline
\end{tabular}




\begin{tabular}{|c|c|c|c|c|}
\hline 14 & $\begin{array}{l}\text { being overwhelmed by the switch to digital } \\
\text { media/class/teaching }\end{array}$ & 10303 & 0.22 & $5.53 e-111$ \\
\hline 15 & $\begin{array}{l}\text { feeling relieved by the absence of private } \\
\text { obligations }\end{array}$ & 10303 & -0.22 & $2.58 e-108$ \\
\hline 16 & burden to forego cultural events and visits & 10303 & 0.19 & $3.26 e-80$ \\
\hline 17 & burden of financial consequences & 10303 & 0.18 & $4.99 \mathrm{e}-78$ \\
\hline 18 & $\begin{array}{l}\text { feeling good to spend more time with } \\
\text { family / partner /child(ren) }\end{array}$ & 10303 & -0.15 & $6.86 e-51$ \\
\hline 19 & feeling more in control of own situation & 10303 & -0.13 & $8.46 e-39$ \\
\hline 20 & $\begin{array}{l}\text { being afraid that soon it will no longer be } \\
\text { possible to buy groceries or medication }\end{array}$ & 10303 & 0.10 & $1.35 e-25$ \\
\hline \multicolumn{5}{|c|}{ Anxiety level } \\
\hline 1 & confidence to overcome the crisis well & 10303 & -0.32 & $1.57 e-244$ \\
\hline 2 & burden due to thoughts about the future & 10303 & 0.28 & $6.17 e-190$ \\
\hline 3 & burden of living alone & 2169 & 0.28 & $1.65 \mathrm{e}-39$ \\
\hline 4 & burden due to changes at work & 6457 & 0.26 & $3.14 \mathrm{e}-103$ \\
\hline 5 & burden due to changes at school & 1582 & 0.22 & $6.13 e-19$ \\
\hline 6 & getting infected of the virus & 10303 & 0.21 & $1.04 \mathrm{e}-104$ \\
\hline 7 & $\begin{array}{l}\text { burden of not being able to spend more } \\
\text { time privately with others }\end{array}$ & 10303 & 0.19 & $2.81 e-88$ \\
\hline 8 & dying because of the virus & 10303 & 0.19 & $2.41 \mathrm{e}-87$ \\
\hline 9 & having more time for relaxation & 10303 & -0.17 & $2.03 e-71$ \\
\hline 10 & $\begin{array}{l}\text { fear that a close person get infected by the } \\
\text { virus }\end{array}$ & 10303 & 0.16 & $4.11 \mathrm{e}-63$ \\
\hline 11 & $\begin{array}{l}\text { fear that a close person die because of } \\
\text { virus }\end{array}$ & 10303 & 0.16 & $2.31 e-62$ \\
\hline 12 & $\begin{array}{l}\text { the burden to keep the two meter security } \\
\text { distance }\end{array}$ & 10303 & 0.16 & $1.05 e-59$ \\
\hline
\end{tabular}




\begin{tabular}{|c|c|c|c|c|}
\hline 13 & $\begin{array}{l}\text { burden of not being able to spend more } \\
\text { time with others in my working life }\end{array}$ & 10303 & 0.16 & $8.10 e-57$ \\
\hline 14 & burden of financial consequences & 10303 & 0.15 & $1.64 \mathrm{e}-55$ \\
\hline 15 & the burden of reduced personal freedom & 10303 & 0.15 & $4.72 \mathrm{e}-53$ \\
\hline 16 & $\begin{array}{l}\text { feeling relieved by the absence of } \\
\text { professional / school obligations }\end{array}$ & 10303 & -0.15 & $8.58 e-50$ \\
\hline 17 & feeling more in control of own situation & 10303 & -0.13 & $9.31 e-38$ \\
\hline 18 & $\begin{array}{l}\text { feeling relieved by the absence of private } \\
\text { obligations }\end{array}$ & 10303 & -0.12 & $8.07 e-37$ \\
\hline 19 & increased conflicts at home & 8134 & 0.12 & $1.08 \mathrm{e}-27$ \\
\hline 20 & $\begin{array}{l}\text { being overwhelmed by the switch to digital } \\
\text { media/class/teaching }\end{array}$ & 10303 & 0.12 & $8.99 e-32$ \\
\hline 21 & burden to forego cultural events and visits & 10303 & 0.11 & $4.08 \mathrm{e}-31$ \\
\hline 22 & $\begin{array}{l}\text { the burden of childcare for people with } \\
\text { children }\end{array}$ & 2230 & 0.11 & $1.26 \mathrm{e}-07$ \\
\hline
\end{tabular}


Table 3: Logit regression for 'resilient' category.

Odds ratio and $95 \%$ confidence intervals obtained from logit regression model comparing 'resilient' participants to others.

\begin{tabular}{|c|c|c|c|c|}
\hline & & Wave 1 & Wave 2 & $\begin{array}{l}\text { Wave } 2 \\
\text { (matched) }\end{array}$ \\
\hline Variable & Reference group & OR & OR & OR \\
\hline Prior psychiatric disorder - No & Yes & $4.3[3.8 ; 4.9]$ & $4.3[3.8 ; 4.9]$ & $4.1[3.4 ; 4.9]$ \\
\hline Age group 14-24 & $35-44$ & $0.7[0.5 ; 0.8]$ & $0.6[0.5 ; 0.8]$ & $0.6[0.5 ; 0.8]$ \\
\hline Age group 25-34 & $35-44$ & $0.8[0.7 ; 0.9]$ & $0.8[0.7 ; 0.9]$ & $0.7[0.6 ; 0.9]$ \\
\hline Age group 45-54 & $35-44$ & $1.1[1 ; 1.3]$ & $1.3[1.1 ; 1.4]$ & $1.2[1 ; 1.4]$ \\
\hline Age group 55-64 & $35-44$ & $1.7[1.5 ; 2]$ & $1.9[1.6 ; 2.1]$ & $1.8[1.4 ; 2.2]$ \\
\hline Age group $>=65$ & $35-44$ & $3.8[2.8 ; 5.2]$ & $2.8[2.2 ; 3.5]$ & $3.6[2.4 ; 5.5]$ \\
\hline Gender - Male & female & $1.8[1.6 ; 2]$ & $1.6[1.4 ; 1.8]$ & $1.6[1.4 ; 1.8]$ \\
\hline $\begin{array}{l}\text { Profession Working affected by } \\
\text { restrictions }\end{array}$ & Working-NotAffected & $0.8[0.7 ; 0.9]$ & $0.8[0.7 ; 1]$ & $0.9[0.7 ; 1.1]$ \\
\hline Profession Job seeking & Working-NotAffected & $0.5[0.3 ; 0.6]$ & $0.5[0.4 ; 0.6]$ & $0.4[0.3 ; 0.7]$ \\
\hline $\begin{array}{l}\text { Profession Study - school - } \\
\text { apprenticeship }\end{array}$ & Working-NotAffected & $0.8[0.6 ; 0.9]$ & $0.6[0.5 ; 0.7]$ & $0.5[0.4 ; 0.7]$ \\
\hline Profession AHV-IV & Working-NotAffected & $0.8[0.6 ; 1]$ & $1.1[0.9 ; 1.3]$ & $1[0.7 ; 1.4]$ \\
\hline Profession House-wife/husband & Working-NotAffected & $0.9[0.8 ; 1.1]$ & $1.3[1.1 ; 1.6]$ & $1.3[1 ; 1.7]$ \\
\hline
\end{tabular}




\section{Supplementary data}

\section{Supplementary Figure 1: Decrease in anxiety related variables between Wave 1 and Wave 2.}

Comparison performed on unmatched datasets.

Proportion: proportion of participants within a category, relative to total number in a given population wave.
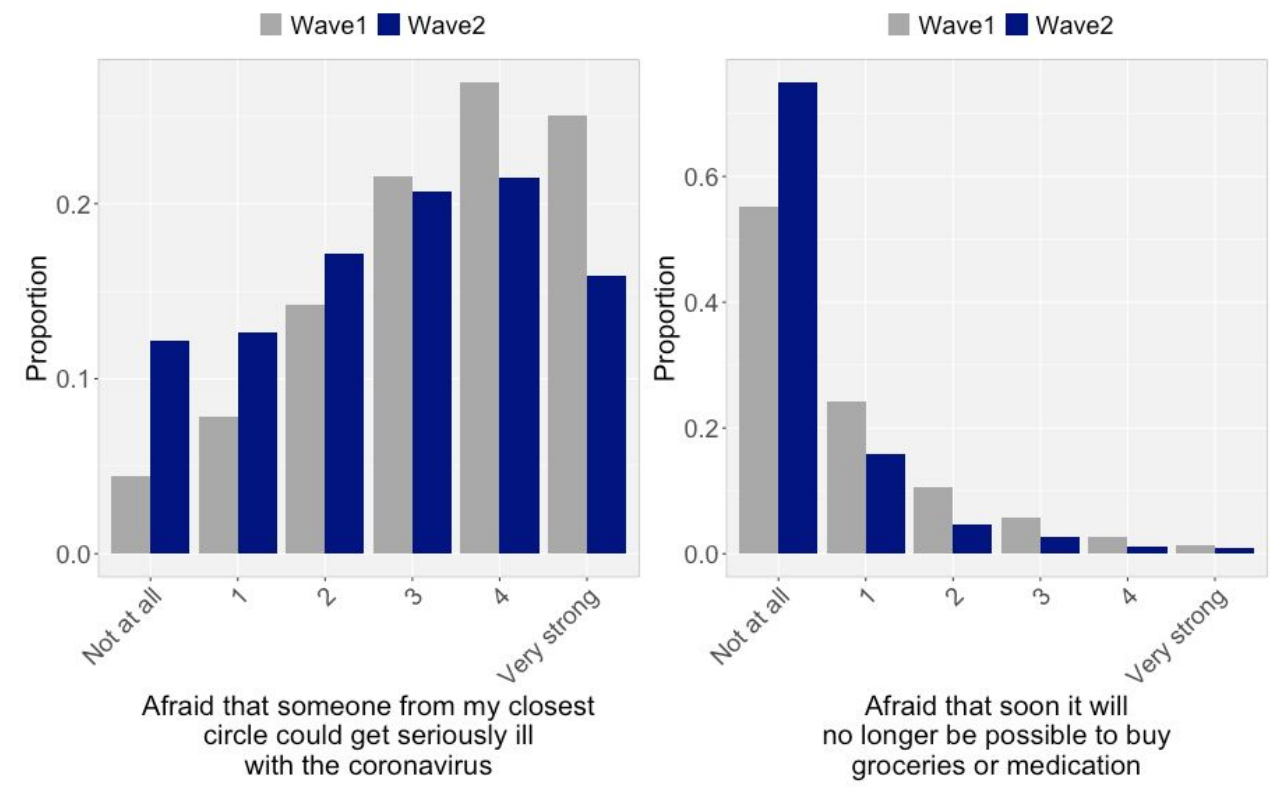
Supplementary Figure 2: Difference in perception of governmental restrictions between Wave 1 and Wave2.

Comparison performed on unmatched datasets.

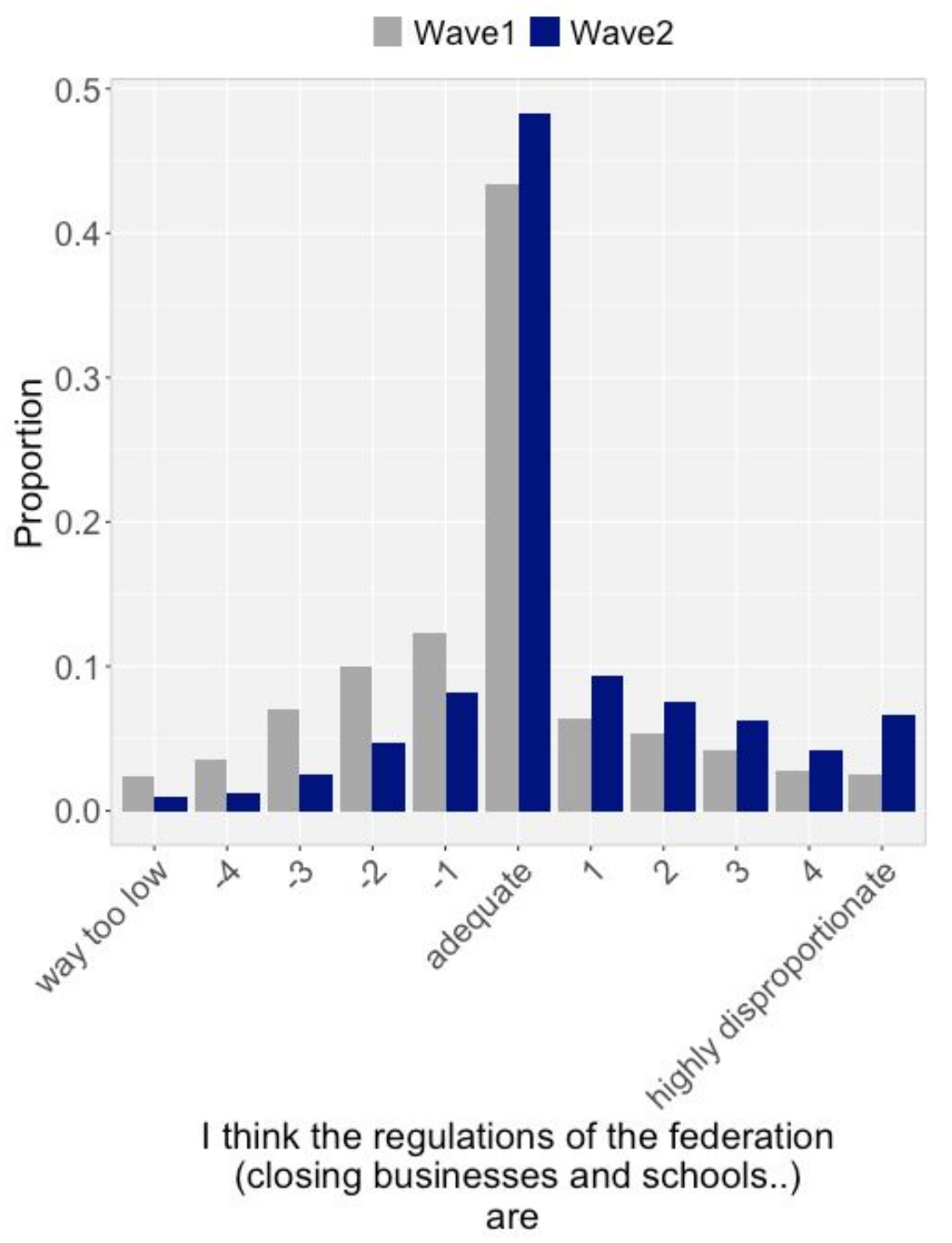




\section{Supplementary Figure 3a: Effects of age on PHQ None-minimal category, before and during lockdown.}

Plot of marginal effects estimated from Logit regression model on 'PHQ None-minimal' category, before and during lockdown. Error bars represent $95 \%$ confidence intervals. Please note: "Lockdown" in wave 2 refers to the time of partial deconfinement.

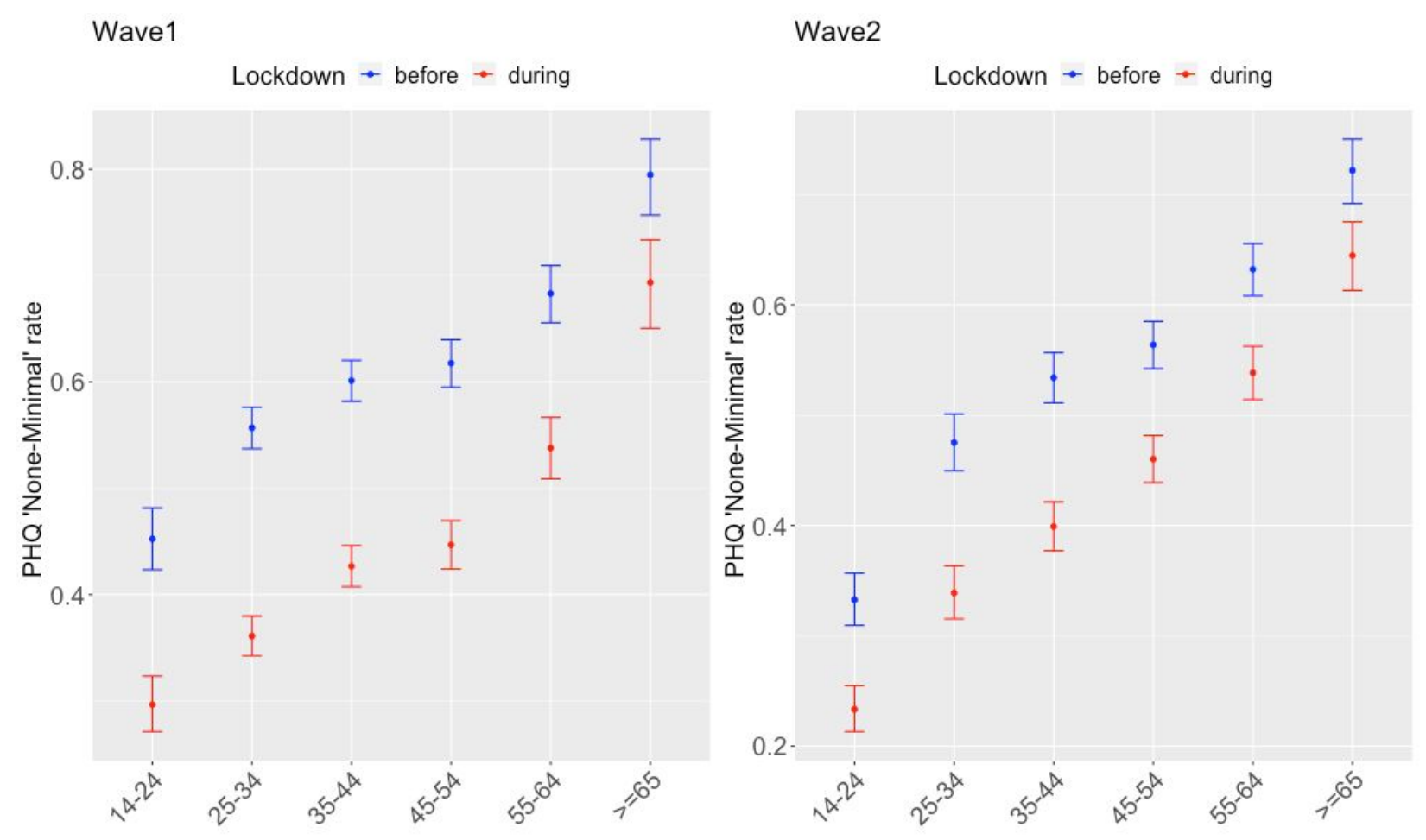


Supplementary Figure 3b: Effects of sex on PHQ None-minimal category, before and during the lockdown.

Plot of marginal effects estimated from Logit regression model on 'PHQ None-minimal' category, before and during lockdown. Error bars represent $95 \%$ confidence intervals. Please note: "Lockdown" in wave 2 refers to the time of partial deconfinement.

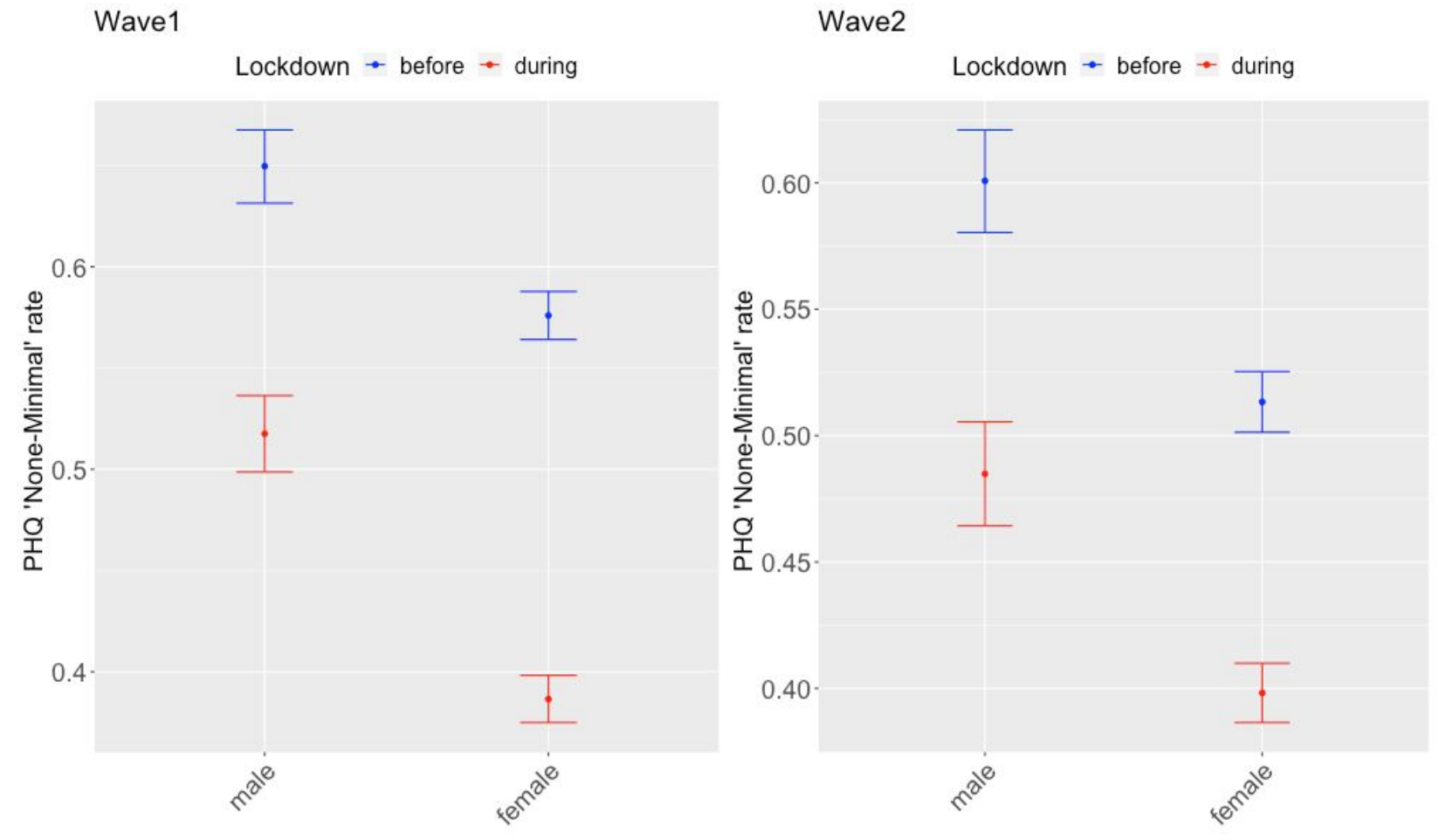




\section{Supplementary Figure 3c: Effects of prior psychiatric disorder on PHQ None-minimal category, before and during lockdown.}

Plot of marginal effects estimated from Logit regression model on 'PHQ None-minimal' category, before and during lockdown. Error bars represent $95 \%$ confidence intervals. Please note: "Lockdown" in wave 2 refers to the time of partial deconfinement.

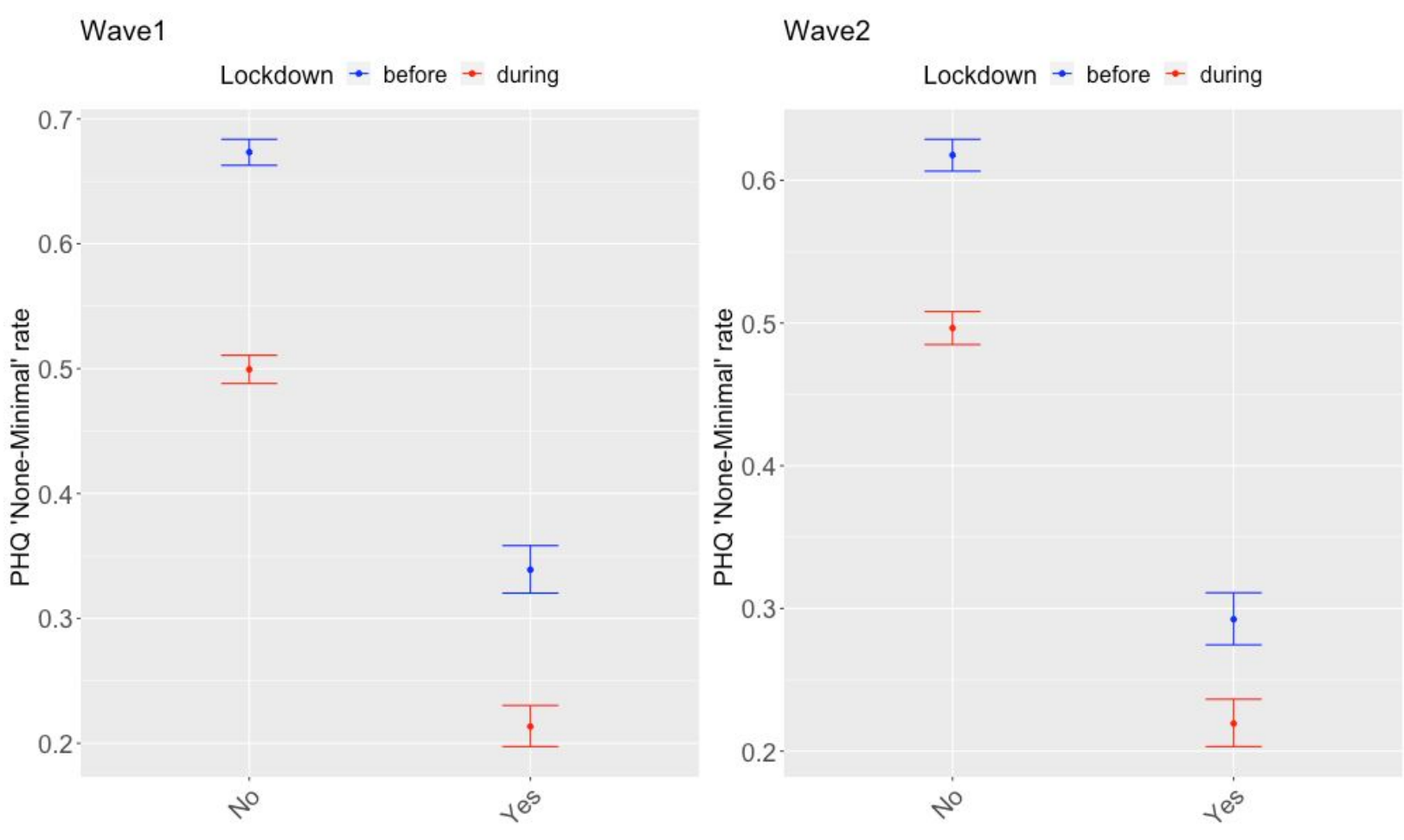




\section{Supplementary Table 1: Comparison of socio-demographics characteristics between Wave 1 and Wave 2.}

Only factors differing between waves with at least small effect size (Cramer's $V \geq 0.1$ ) are shown.

\begin{tabular}{|c|c|c|c|c|}
\hline Item & $\begin{array}{l}\mathrm{N} \\
\text { Wave1 }\end{array}$ & $\begin{array}{l}\mathbf{N} \\
\text { Wave2 }\end{array}$ & p-value & $\begin{array}{l}\text { Effect size } \\
\text { (Cramer's V) }\end{array}$ \\
\hline Canton & 10472 & 10303 & $2.6 e-229$ & 0.225 \\
\hline Age group & 10472 & 10303 & $3.5 e-154$ & 0.188 \\
\hline Age of children & 10472 & 10303 & $2.5 e-92$ & 0.145 \\
\hline Activity & 10472 & 10303 & $3.0 e-72$ & 0.132 \\
\hline Education & 10472 & 10303 & $5.9 e-60$ & 0.118 \\
\hline Household & 10472 & 10303 & $6.6 e-45$ & 0.104 \\
\hline
\end{tabular}




\section{Supplementary Table 2: Comparison of pandemic-related variables between Wave 1 and Wave 2 .}

Stress, anxiety and PHQ scores variables not included in this table.

Unmatched: Cramer's V effect size observed in unmatched datasets.

Matched: Cramer's $V$ effect size observed in matched datasets.

Only associations with Cramer's $V$ effect size $\geq 0.1$ in matched or unmatched comparisons are shown.

\begin{tabular}{|c|c|c|c|c|}
\hline & & & Effect size & \\
\hline Label & Nave 1 & N & Unmatched & Matched \\
\hline I stay informed about coronavirus news & 10472 & 10303 & 0.4344 & 0.4163 \\
\hline I voluntarily abstain from going out of my apartment. & 10472 & 10303 & 0.2362 & 0.2074 \\
\hline $\begin{array}{l}\text { I think the regulations of the federation (closing businesses and } \\
\text { schools, request to stay at home) are all in all }\end{array}$ & 10472 & 10303 & 0.2269 & 0.1954 \\
\hline $\begin{array}{l}\text { Afraid that soon it will no longer be possible to buy groceries or } \\
\text { medication }\end{array}$ & 10472 & 10303 & 0.2119 & 0.1939 \\
\hline $\begin{array}{l}\text { Afraid that someone from my closest circle could get seriously ill with } \\
\text { the coronavirus }\end{array}$ & 10472 & 10303 & 0.1953 & 0.1624 \\
\hline $\begin{array}{l}\text { Afraid that someone from my closest circle could die from the } \\
\text { coronavirus }\end{array}$ & 10472 & 10303 & 0.1926 & 0.1567 \\
\hline $\begin{array}{l}\text { To maintain my social contacts, I increasingly use } \\
\text { smartphones/computers/telephones }\end{array}$ & 10472 & 10303 & 0.1491 & 0.1371 \\
\hline I currently work/study from home (home office/homeschooling). & 10472 & 10303 & 0.1466 & 0.1127 \\
\hline I have to go to work. & 10472 & 10303 & 0.1439 & 0.1537 \\
\hline
\end{tabular}




\begin{tabular}{|c|c|c|c|c|}
\hline I continue receiving professional psychological support & 1466 & 1393 & 0.1283 & 0.09751 \\
\hline I have to/can work more/less in the current situation. & 10472 & 10303 & 0.1228 & 0.1068 \\
\hline The financial consequences burden me. & 10472 & 10303 & 0.1189 & 0.09431 \\
\hline Corona test & 10472 & 10303 & 0.1169 & 0.1197 \\
\hline Afraid that I will get seriously ill with the coronavirus & 10472 & 10303 & 0.1159 & 0.09147 \\
\hline Afraid that I could die from the coronavirus & 10472 & 10303 & 0.1141 & 0.09938 \\
\hline I take care of my children at home & 2485 & 2885 & 0.1141 & 0.1299 \\
\hline $\begin{array}{l}\text { It is a burden to forego cultural events and visits (museum, theater, } \\
\text { concerts) }\end{array}$ & 10472 & 10303 & 0.1057 & 0.09904 \\
\hline It is a burden to keep to the 2-meter security distance & 10472 & 10303 & 0.1029 & 0.0906 \\
\hline
\end{tabular}




\section{Supplementary Table 3: Comparison of PHQ 'vulnerable' participants to the remaining participants in terms of socio-demographic and history of psychiatric disorder.}

Effect size: Cramer's $\vee$. Factors with $\vee \geq 0.1$ across wave 1 and wave 2 are marked $\left({ }^{*}\right)$.

\begin{tabular}{|c|c|c|c|c|c|c|c|c|c|}
\hline \multirow[b]{2}{*}{ Label } & \multicolumn{3}{|c|}{ Wave 1} & \multicolumn{3}{|c|}{ Wave 2} & \multicolumn{3}{|c|}{ Wave 2 (matched) } \\
\hline & N1 & N2 & Effect & N1 & N2 & $\begin{array}{l}\text { Effect } \\
\text { size }\end{array}$ & N1 & N2 & $\begin{array}{l}\text { Effect } \\
\text { size }\end{array}$ \\
\hline \multicolumn{10}{|l|}{ Socio-demographic } \\
\hline Gender & 742 & 9696 & 0.04 & 829 & 9416 & 0.04 & 413 & 4707 & 0.03 \\
\hline Age group & 746 & 9726 & 0.07 & 837 & 9466 & 0.11 & 413 & 4707 & 0.09 \\
\hline Canton & 746 & 9726 & 0.01 & 837 & 9466 & 0.04 & 413 & 4707 & 0.05 \\
\hline Household & 746 & 9726 & 0.02 & 837 & 9466 & 0.01 & 413 & 4707 & 0.02 \\
\hline Religion & 746 & 9726 & 0 & 837 & 9466 & 0 & 413 & 4707 & 0.02 \\
\hline Has child(-ren) & 746 & 9726 & 0.03 & 837 & 9466 & 0.05 & 413 & 4707 & 0.05 \\
\hline Education & 746 & 9726 & 0.07 & 837 & 9466 & 0.04 & 413 & 4707 & 0.03 \\
\hline Activity & 746 & 9726 & 0.06 & 837 & 9466 & 0.11 & 413 & 4707 & 0.11 \\
\hline Independent & 471 & 6921 & 0.02 & 477 & 5996 & 0 & 252 & 3286 & 0.01 \\
\hline Employed & 471 & 6921 & 0.02 & 477 & 5996 & 0.02 & 252 & 3286 & 0.02 \\
\hline $\begin{array}{l}\text { Working in a small or medium-sized company } \\
\text { (SME) }\end{array}$ & 471 & 6921 & 0 & 477 & 5996 & 0 & 252 & 3286 & 0.01 \\
\hline Working in a private company & 471 & 6921 & 0.01 & 477 & 5996 & 0 & 252 & 3286 & 0.02 \\
\hline
\end{tabular}




\begin{tabular}{|c|c|c|c|c|c|c|c|c|c|}
\hline Working in a public company & 471 & 6921 & 0.01 & 477 & 5996 & 0.02 & 252 & 3286 & 0.04 \\
\hline $\begin{array}{l}\text { Working in a sector impacted by government } \\
\text { action }\end{array}$ & 471 & 6921 & 0.03 & 477 & 5996 & 0.02 & 252 & 3286 & 0.01 \\
\hline Working with patients or care sector & 471 & 6921 & 0.02 & 477 & 5996 & 0.02 & 252 & 3286 & 0.01 \\
\hline Working as a teacher & 471 & 6921 & 0.01 & 477 & 5996 & 0 & 252 & 3286 & 0.01 \\
\hline $\begin{array}{l}\text { Working as a teacher OR working in the sale of } \\
\text { groceries }\end{array}$ & 471 & 6921 & 0 & 477 & 5996 & 0.02 & 252 & 3286 & 0.01 \\
\hline $\begin{array}{l}\text { Working in sale of groceries or in delivery of } \\
\text { goods }\end{array}$ & 471 & 6921 & 0.02 & 477 & 5996 & 0.02 & 252 & 3286 & 0.01 \\
\hline Habitation & 746 & 9726 & 0.01 & 837 & 9466 & 0.04 & 413 & 4707 & 0.04 \\
\hline Age of children & 746 & 9726 & 0.03 & 837 & 9466 & 0.06 & 413 & 4707 & 0.06 \\
\hline \multicolumn{10}{|l|}{ Prior psychiatric disorder } \\
\hline Prior psychiatric disorder $\left({ }^{*}\right)$ & 746 & 9726 & 0.17 & 837 & 9466 & 0.13 & 413 & 4707 & 0.12 \\
\hline Pre-existing mental illness: Depression (*) & 746 & 9726 & 0.16 & 837 & 9466 & 0.12 & 413 & 4707 & 0.12 \\
\hline Pre-existing mental illness: Schizophrenia & 746 & 9726 & 0.03 & 837 & 9466 & 0.01 & 413 & 4707 & 0.02 \\
\hline $\begin{array}{l}\text { Pre-existing mental illness: Post-traumatic stress } \\
\text { disorder }\end{array}$ & 746 & 9726 & 0.11 & 837 & 9466 & 0.08 & 413 & 4707 & 0.06 \\
\hline Pre-existing mental illness: Anxiety disorder $\left({ }^{*}\right)$ & 746 & 9726 & 0.14 & 837 & 9466 & 0.11 & 413 & 4707 & 0.11 \\
\hline $\begin{array}{l}\text { Pre-existing mental illness: } \\
\text { Obsessive-compulsive disorder }\end{array}$ & 746 & 9726 & 0.08 & 837 & 9466 & 0.02 & 413 & 4707 & 0.02 \\
\hline Pre-existing mental illness: other & 746 & 9726 & 0.07 & 837 & 9466 & 0.06 & 413 & 4707 & 0.04 \\
\hline $\begin{array}{l}\text { Pre-existing mental illness: Psychotropic } \\
\text { medication }\end{array}$ & 746 & 9726 & 0.1 & 837 & 9466 & 0.07 & 413 & 4707 & 0.06 \\
\hline
\end{tabular}




\begin{tabular}{|l|l|l|l|l|l|l|l|l|l|}
\hline $\begin{array}{l}\text { I had regular professional psychological support } \\
\text { before the coronavirus crisis. }\end{array}$ & 746 & 9726 & 0.13 & 837 & 9466 & 0.09 & 413 & 4707 & 0.09 \\
\hline $\begin{array}{l}\text { I continue receiving professional psychological } \\
\text { support }\end{array}$ & 227 & 1239 & 0.01 & 207 & 1186 & 0.01 & 97 & 564 & 0.01 \\
\hline
\end{tabular}




\section{Supplementary Table 4: Comparison of PHQ 'resilient' participants to the remaining participants in terms of socio-demographic factors and prior psychiatric disorder.}

Effect size: Cramer's $\vee$. Factors with $\vee \geq 0.1$ across wave 1 and wave 2 are marked $\left({ }^{*}\right)$.

\begin{tabular}{|c|c|c|c|c|c|c|c|c|c|}
\hline \multirow[b]{2}{*}{ Label } & \multicolumn{3}{|c|}{ Wave 1} & \multicolumn{3}{|c|}{ Wave 2} & \multicolumn{3}{|c|}{ Wave 2 Matched } \\
\hline & N1 & N2 & $\begin{array}{l}\text { Effect } \\
\text { size }\end{array}$ & N1 & N2 & $\begin{array}{l}\text { Effe } \\
\text { ct } \\
\text { size }\end{array}$ & N1 & N2 & $\begin{array}{l}\text { Effect } \\
\text { size }\end{array}$ \\
\hline \multicolumn{10}{|l|}{ Socio-demographic } \\
\hline Gender $(*)$ & 3817 & 6621 & 0.15 & 3693 & 6552 & 0.12 & 1764 & 3356 & 0.12 \\
\hline Age group $\left({ }^{*}\right)$ & 3824 & 6648 & 0.19 & 3704 & 6599 & 0.26 & 1764 & 3356 & 0.26 \\
\hline Canton & 3824 & 6648 & 0.03 & 3704 & 6599 & 0.04 & 1764 & 3356 & 0.04 \\
\hline Household & 3824 & 6648 & 0.03 & 3704 & 6599 & 0.01 & 1764 & 3356 & 0.02 \\
\hline Religion & 3824 & 6648 & 0.01 & 3704 & 6599 & 0.03 & 1764 & 3356 & 0.05 \\
\hline Has child(-ren) & 3824 & 6648 & 0.06 & 3704 & 6599 & 0.15 & 1764 & 3356 & 0.15 \\
\hline Education & 3824 & 6648 & 0.08 & 3704 & 6599 & 0.1 & 1764 & 3356 & 0.08 \\
\hline Activity $\left({ }^{*}\right)$ & 3824 & 6648 & 0.15 & 3704 & 6599 & 0.21 & 1764 & 3356 & 0.21 \\
\hline Independent & 2815 & 4577 & 0.02 & 2423 & 4050 & 0.06 & 1271 & 2267 & 0.08 \\
\hline Employed & 2815 & 4577 & 0.01 & 2423 & 4050 & 0.02 & 1271 & 2267 & 0.02 \\
\hline Working in a small or medium-sized company (SME) & 2815 & 4577 & 0 & 2423 & 4050 & 0.01 & 1271 & 2267 & 0.01 \\
\hline Working in a private company & 2815 & 4577 & 0.02 & 2423 & 4050 & 0.01 & 1271 & 2267 & 0.01 \\
\hline Working in a public company & 2815 & 4577 & 0.02 & 2423 & 4050 & 0.02 & 1271 & 2267 & 0.01 \\
\hline Working in a sector impacted by government action & 2815 & 4577 & 0.06 & 2423 & 4050 & 0.03 & 1271 & 2267 & 0.02 \\
\hline Working with patients or care sector & 2815 & 4577 & 0.03 & 2423 & 4050 & 0.02 & 1271 & 2267 & 0.02 \\
\hline Working as a teacher & 2815 & 4577 & 0 & 2423 & 4050 & 0.03 & 1271 & 2267 & 0.02 \\
\hline $\begin{array}{l}\text { Working as a teacher OR working in the sale of } \\
\text { groceries }\end{array}$ & 2815 & 4577 & 0 & 2423 & 4050 & 0.03 & 1271 & 2267 & 0.03 \\
\hline
\end{tabular}




\begin{tabular}{|c|c|c|c|c|c|c|c|c|c|}
\hline Working in sale of groceries or in delivery of goods & 2815 & 4577 & 0.01 & 2423 & 4050 & 0 & 1271 & 2267 & 0.01 \\
\hline Habitation & 3824 & 6648 & 0.05 & 3704 & 6599 & 0.07 & 1764 & 3356 & 0.07 \\
\hline Age of children & 3824 & 6648 & 0.09 & 3704 & 6599 & 0.18 & 1764 & 3356 & 0.17 \\
\hline \multicolumn{10}{|l|}{ Prior psychiatric disorder } \\
\hline Prior psychiatric disorder $\left({ }^{*}\right)$ & 3824 & 6648 & 0.25 & 3704 & 6599 & 0.26 & 1764 & 3356 & 0.24 \\
\hline Pre-existing mental illness: Depression (*) & 3824 & 6648 & 0.22 & 3704 & 6599 & 0.22 & 1764 & 3356 & 0.2 \\
\hline Pre-existing mental illness: Schizophrenia & 3824 & 6648 & 0.04 & 3704 & 6599 & 0.01 & 1764 & 3356 & 0.01 \\
\hline $\begin{array}{l}\text { Pre-existing mental illness: Post-traumatic stress } \\
\text { disorder }\left(^{*}\right)\end{array}$ & 3824 & 6648 & 0.1 & 3704 & 6599 & 0.12 & 1764 & 3356 & 0.1 \\
\hline Pre-existing mental illness: Anxiety disorder $\left({ }^{*}\right)$ & 3824 & 6648 & 0.19 & 3704 & 6599 & 0.19 & 1764 & 3356 & 0.18 \\
\hline $\begin{array}{l}\text { Pre-existing mental illness: Obsessive-compulsive } \\
\text { disorder }\end{array}$ & 3824 & 6648 & 0.07 & 3704 & 6599 & 0.07 & 1764 & 3356 & 0.05 \\
\hline Pre-existing mental illness: other & 3824 & 6648 & 0.09 & 3704 & 6599 & 0.1 & 1764 & 3356 & 0.09 \\
\hline $\begin{array}{l}\text { Pre-existing mental illness: Psychotropic medication } \\
\left({ }^{*}\right)\end{array}$ & 3824 & 6648 & 0.13 & 3704 & 6599 & 0.12 & 1764 & 3356 & 0.1 \\
\hline
\end{tabular}




\section{References}

[1] B. S. McEwen, "Stress, Adaptation, and Disease: Allostasis and Allostatic Load," Annals of the New York Academy of Sciences, vol. 840, no. 1, pp. 33-44, 1998, doi: 10.1111/j.1749-6632.1998.tb09546.x.

[2] E. R. de Kloet, M. Joëls, and F. Holsboer, "Stress and the brain: from adaptation to disease," Nat Rev Neurosci, vol. 6, no. 6, pp. 463-475, Jun. 2005, doi: 10.1038/nrn1683.

[3] E. A. Holmes et al., "Multidisciplinary research priorities for the COVID-19 pandemic: a call for action for mental health science," The Lancet Psychiatry, Apr. 2020, doi: 10.1016/S2215-0366(20)30168-1.

[4] M. A. Reger, I. H. Stanley, and T. E. Joiner, "Suicide Mortality and Coronavirus Disease 2019-A Perfect Storm?," JAMA Psychiatry, Apr. 2020, doi: 10.1001/jamapsychiatry.2020.1060.

[5] S. K. Brooks et al., "The psychological impact of quarantine and how to reduce it: rapid review of the evidence," The Lancet, vol. 395, no. 10227, pp. 912-920, Mar. 2020, doi: 10.1016/S0140-6736(20)30460-8.

[6] W. P. Jayawardene, D. K. Lohrmann, R. G. Erbe, and M. R. Torabi, "Effects of preventive online mindfulness interventions on stress and mindfulness: A meta-analysis of randomized controlled trials," Preventive Medicine Reports, vol. 5, pp. 150-159, Mar. 2017, doi: 10.1016/j.pmedr.2016.11.013.

[7] B. Stubbs et al., "An examination of the anxiolytic effects of exercise for people with anxiety and stress-related disorders: A meta-analysis," Psychiatry Research, vol. 249, pp. 102-108, Mar. 2017, doi: 10.1016/j.psychres.2016.12.020.

[8] D. J. Leiner, SoSci Survey. 2014.

[9] K. Kroenke and R. L. Spitzer, "The PHQ-9: A New Depression Diagnostic and Severity Measure," Psychiatric Annals, vol. 32, no. 9, pp. 509-515, Sep. 2002, doi: 10.3928/0048-5713-20020901-06. 